Prepared for the U.S. Department of Energy

under Contract DE-AC05-76RL01830

\title{
Social Networking for Emergency Management and Public Safety
}

\author{
AM Lesperance \\ MA Godinez \\ JR Olson
}

August 2010

\section{Pacific Northwest}

NATIONAL LABORATORY

Proudly Operated by Battelle Since 1965 



\section{DISCLAIMER}

This report was prepared as an account of work sponsored by an agency of the United States Government. Neither the United States Government nor any agency thereof, nor Battelle Memorial Institute, nor any of their employees, makes any warranty, express or implied, or assumes any legal liability or responsibility for the accuracy, completeness, or usefulness of any information, apparatus, product, or process disclosed, or represents that its use would not infringe privately owned rights. Reference herein to any specific commercial product, process, or service by trade name, trademark, manufacturer, or otherwise does not necessarily constitute or imply its endorsement, recommendation, or favoring by the United States Government or any agency thereof, or Battelle Memorial Institute. The views and opinions of authors expressed herein do not necessarily state or reflect those of the United States Government or any agency thereof.

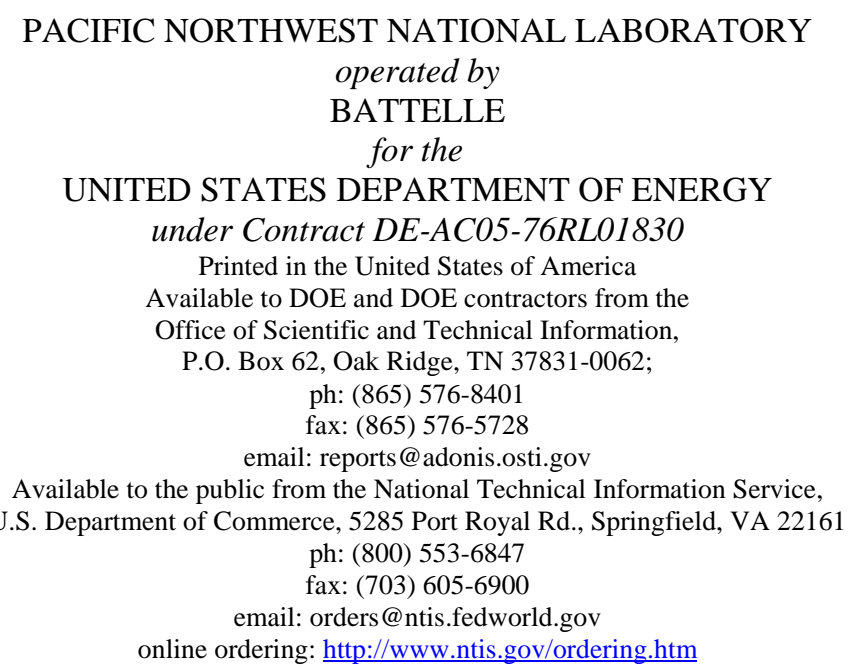



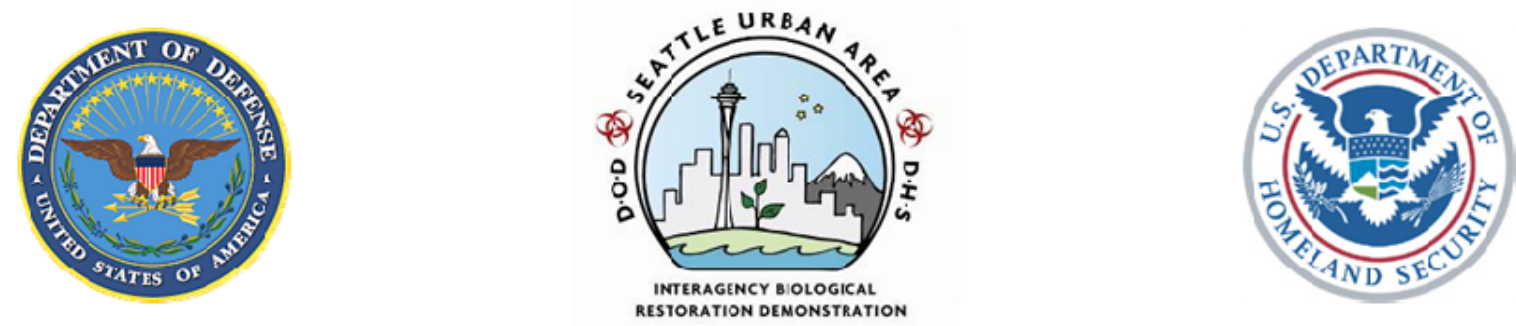

\title{
Social Networking for Emergency Management and Public Safety
}

\author{
August 2010
}

Prepared for the Interagency Biological Restoration Demonstration Program a program jointly funded by the Department of Defense, Defense Threat Reduction Agency and the Department of Homeland Security, Science \& Technology Directorate 



\section{Acknowledgements}

The authors would like to acknowledge and thank the public information officers from the emergency response and public health organizations as well as the industry representatives and subject matter experts who participated in this workshop. Their contributions of operational perspective and technical expertise were invaluable. A special thank you to John Mower and Stacey Tyler from Cubic Applications, and Adam Wynne, Jared Chase, Jenna Larson, Chris Toomey and Regina Lundgren, representing PNNL, for making this workshop a success. We would also like to thank the U.S. Department of Homeland Security and the U.S. Department of Defense for funding the Interagency Biological Restoration Demonstration program that supported the workshop. 


\section{Executive Summary}

On March 10, 2010 the workshop titled Social Networking for Emergency Management and Public Safety was held in Seattle, WA. The objective of this workshop was to showcase ways social media networking technologies can be used to support emergency management and public safety operations. The workshop highlighted the current state of social networking and where this dynamic engagement is heading, demonstrated some of the more commonly used technologies, highlighted case studies on how these tools have been used in a variety of jurisdictions and engaged the private sector on how these tools might serve as a conduit for two way communication between with the public sector to address regional recovery issues and decision making.

The workshop was supported by the Interagency Biological Restoration Demonstration Project, a project looking at long-term recovery issues from a wide area anthrax attack which is supported by the U.S. Department of Defense and U.S. Department of Homeland Security.

This report summarizes the information presented by the keynote speakers and panelists and lays out conclusions on where the tools are today and their potential role in emergency response planning and implementation now and in the future.

The general consensus of participants was that social media tools can help communicate with the public in emergencies, build situational awareness, and spur recovery. The workshop led to several conclusions:

- Agencies have to trust the public on some level to manage emergencies. All emergencies are local, and public.

- More needs to be studied in regards to how crowd sourcing ${ }^{1}$ leads to robust decisions. Experts in general tend to struggle with the concept that people are turning more and more online to a fan base to help guide their decisions.

- Deferring the release of information is no longer an option. Social media tools can be used; they are being used and used well in the emergency management community. Agencies must consider the ramifications (staffing, resources, control of information) when joining the social media conversation.

- Public demand and competition, even among government agencies, will drive the data. One city cannot afford to remain silent when others are openly sharing.

- People want information, and they expect it immediately. The challenge will be balancing resources and accuracy against the need to produce instant information.

- Government agencies may have to change policies, practices, and skill sets to effectively use social media. They will need to use new terms like branding and dialogue. They may also need to partner more broadly.

\footnotetext{
${ }^{1}$ As defined by Wikipedia.org: A distributed problem-solving and production model. Problems are broadcast to an unknown group of solvers in the form of an open call for solutions. Users, also known as the crowd, typically form into online communities, and the crowd submits solutions.
} 
One of the ways to help build advocacy for the use of social media is to identify champions. Agencies need a strategy and the right person to engage the right stakeholders to develop a model that can be used as an example to build tools that engage regions. A key component of this strategy will be the ability to analyze the tremendous amount of information coming out of social media.

Social media is a new frontier for emergency management. This workshop was a step in learning where and how to take advantage of such tools to safeguard communities and help them recover from crises. 


\section{Contents}

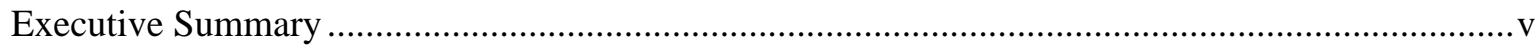

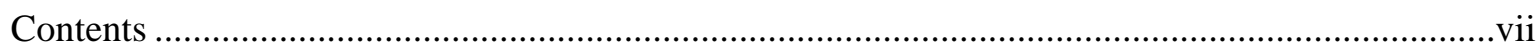

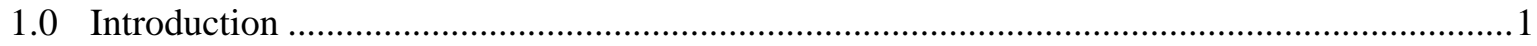

2.0 The Future Is Here: Technologies Being Used Today ...........................................................5

3.0 A View from the Trenches: Private Sector and Critical Service Provider's Perspective ..........7

4.0 More than Tracking Santa: How NORAD and NORTHCOM Use Social Media ..................11

5.0 Tools to Use: Existing Models and Best Practices .............................................................13

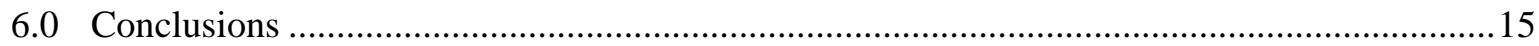

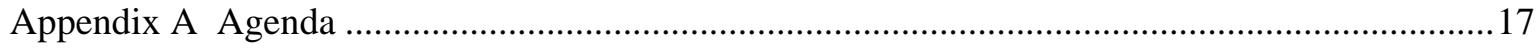

Appendix B Presentations and Handouts ................................................................................... 19

B-1 Glen Woodbury, Director, Center for Homeland Defense and Security Naval

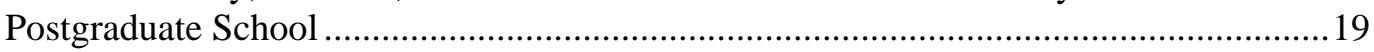

B-2 Lind Simonsen, Community Relations Coordinator, Pierce County Transit.....................25

B-3 James Graybeal, Deputy Chief of Staff for Communications and Director of Public Affairs, NORAD and US Northern Command …..........................................................

B-4 Laurie Van Leuven, Strategic Advisor and Manager, Seattle Public Utilities ..................45

B-5 Leng Caloh, Convergence Editor and Joe Spurr, Web Developer, KPBS .........................51

B-6 Sabra Schneider, Web Master, King County ...................................................................59

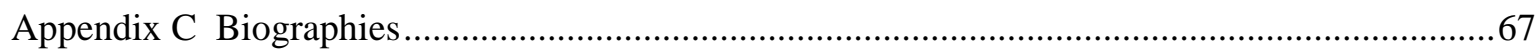

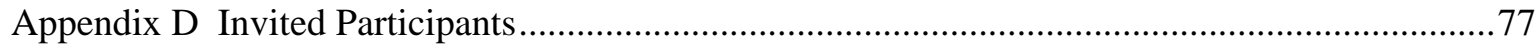

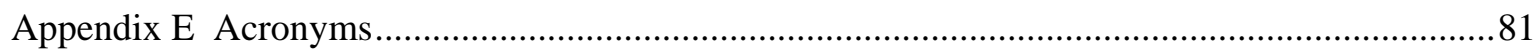




\subsection{Introduction}

Social media networking tools can be used in a variety of ways to support emergency management and public health and safety. But do these expansive tools allow the expression of eloquent information or simply perpetuate noise? Agency staff often question the quality of the data, whether their publics have adopted particular tools, what kind of clarity is possible, and the future of social media. But there is no doubt that the information landscape is changing. Those aged 18 to 34 are embracing social media like never before. Those 45 and older often struggle with the evolving paradigm.

On March 10, 2010, a social media networking workshop, supported by the Interagency Biological Restoration Demonstration Project, under the U.S. Department of Defense and U.S. Department of Homeland Security, was held. Over 100 representatives from federal, state, and local government agencies; the private sector; and the news media met to share case studies, learn from research, and participate in demonstrations of social media tools. The objectives of the workshop were to:

- Highlight the current state of social media networking and where these dynamic tools are heading

- Demonstrate some of the more commonly used technologies

- Highlight case studies on how social media tools have been used in various jurisdictions

- Engage the private sector on how social media tools might serve as a conduit for two-way communication between the private sector and government to address regional recovery issues and decision making.

The workshop was interactive; participants made full use of Twitter ${ }^{2}$ during the event, sharing tweets ${ }^{3}$ with each other and the speakers. One participant blogged during the event, and a panelist, from the city of Philadelphia, spoke to participants through the use of the online networking tool Skype ${ }^{4}$.

This report summarizes the information presented by the keynote speakers and panelists and lays out conclusions on where the tools are today and how they can be best incorporated into emergency response planning and implementation now and in the future. Appendix A provides the full agenda. Other appendixes provide the presentations and handouts, speaker biographies, and participant information.

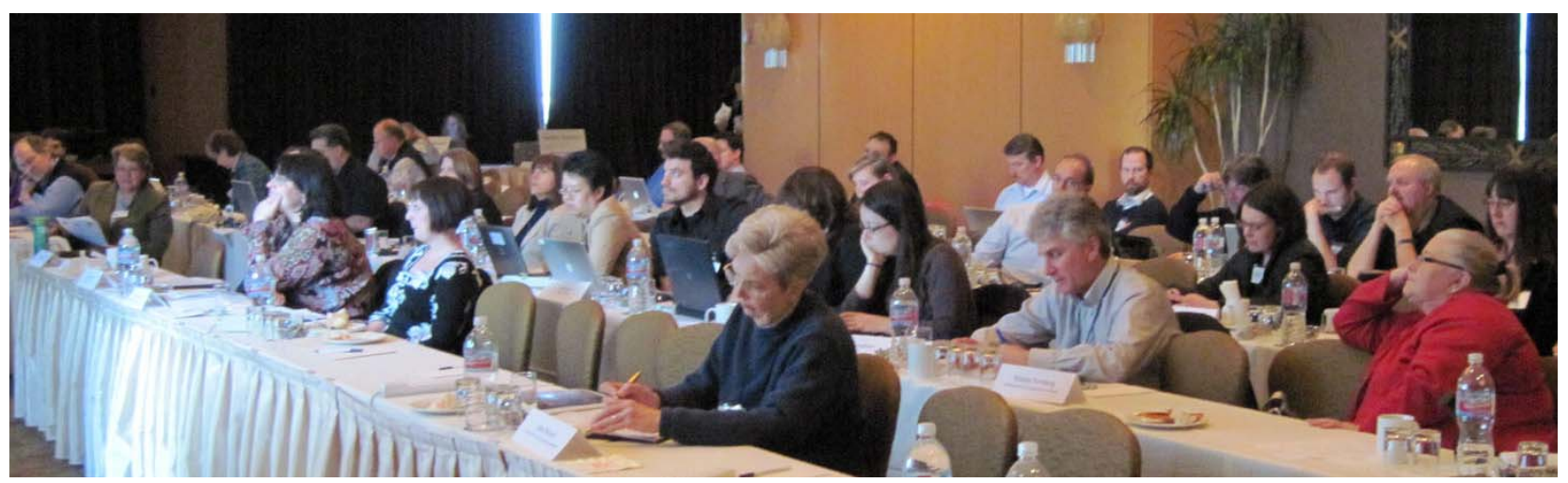

\footnotetext{
2 Social network and blogging site

${ }^{3}$ A post on Twitter

${ }^{4}$ Online networking tool that allows user to interact over the internet similar to a phone call.
} 


\section{To Tweet or Not to Tweet: That is the Question for Public Safety Leaders in the 21st Century}

Glen Woodbury, Director of the Center for Homeland Defense and Security at the Naval Postgraduate School in California, kicked off the workshop by helping attendees think about the key questions before launching into social media. One of the biggest issues is trust, which has many facets:

- How can trust be established among people and organizations who have never interacted before?

- Can data coming from the public be trusted?

- Does the public trust the data coming from government organizations?

- Do government organizations trust the public to interpret data?

\begin{abstract}
"You can establish an electronic relationship with someone you don't know and through that digital relationship you can establish 'electronic trust."' Workshop Participant
\end{abstract}

Trust is a characteristic of human relationships, but it is not easily measured as part of a government process.

Participants shared examples of how trust can be gained or lost. For government participants, factors that build trust included knowing the title and emergency management role of the person on the other end of the social media contact, being

able to verify information in the context of other media, and receiving consistently useful and accurate data from a source. On the other hand, it takes only one mistake to lose trust, and the public appears to find it too easy to latch onto one piece of contrary information among an overwhelming consensus. If people are looking for specific information on a disaster, they may choose to believe it regardless of the source. In addition, the ability to trust in information gleaned from social media seems to change between generations. However, an emergency is not the time to question an information system or the data it generates.

Another complicating factor is the extensive amount of information available through social media. Social media appears in some cases to amplify the sense of risk, and it is not very often that it mitigates the sense of risk. One of the exacerbating factors of this phenomenon is the news media, which tends to perpetuate stories of high risk because they perceive such stories to draw their audiences.

Another key issue is how to determine which, if any, social media systems to use.

Woodbury shared a spectrum of responses that grew out of the Ogma workshop, which explored the policy and strategy implications of new web technologies on homeland security. The various choices outlined in the decision spectrum include the following:
The Ogma Workshop: Exploring the Policy and Strategy Implications of Web 2.0 in the Practice of Homeland Security was held June 30 and July 1, 2009, at the Naval Postgraduate School Center for Homeland Defense and Security in Monterey, California. For more information, see the Center's website at www.chds.us/?conferences/ogma_jun09.

- Suppress: An organization forbids the use of a certain technology. For example, some organizations prohibit staff from watching or posting to YouTube during working hours.

- Defer: An organization decides not to use or engage in technologies or tools even though their use is evident in the operating environment. For example, some organizations are delaying building pages on Facebook until they see how the technology progresses. 
- Adapt: An organization decides to change its operating stance to participate in the same technological environment as its partners or constituents. For example, Washington D.C. Emergency Management used social media at the inauguration of President Obama to gain situational awareness.

- Adopt: An organization decides, in advance of an event, to use technologies and tools that are already in use. For example, the City of Seattle will use communication technology to help manage crowds for the Independence Day celebrations.

- Influence: An organization deliberately influences how a technology or tool is being used, maintained, or operated. For example, during the Iranian election, the U.S. government influenced some social media platforms to hold off maintenance so that Iranian citizens could continue communicating with the world. The Northwest Region provided input on the development of WebEOC, a web-based tool to help manage information in emergency operations centers.

- Design: An organization determines requirements that might be served by new technologies and tools and seeks to design and produce a system to serve those needs. For example, the Federal Emergency Management Agency National Capitol Region is building an innovative tool to gather and share concepts of risk among emergency management agencies.

Many factors can influence where an agency sits on the Web 2.0 support decision spectrum for social media in general and for specific applications. These factors can include resources, trust, attitude of leadership, agency mission, customer service stance, work load, traditions, age, staff understanding, security, perception of the tool, xenophobia, ability to archive information, and potential risks. One challenge is finding the right tool that meets the needs of all those who will be using it for emergency management. Another challenge is that when too many companies work independently to create similar tools, interoperability issues can result. But perhaps the largest challenge lies in agency information systems: such systems tend to be stagnant where social media is dynamic.

Organizations thinking of joining the social media conversation need to be aware that the landscape is dramatically different from other types of communication tools. For one thing, social media cannot be controlled by the organization. In addition, the use of social media can open an organization to threats (negative comments, reverse engineering of systems) from those who are more savvy in the use of these tools. On the other hand, gathering information used in social media to respond to a Freedom of Information Act request can be challenging.

Woodbury challenged participants to consider why they want to use social media tools. Examples include:

- Building trust

- Communicating more effectively

- Saving lives

- Promoting participation in government

- Sharing information

- Building situational awareness

- Fostering transparency.

"In an emergency, you must treat information as a commodity as important as the more traditional and tangible commodities like food, water, and shelter.” Jane Holl Lute, Deputy Secretary, Homeland Security

He also challenged participants to think about information as a commodity: something that is critical to effectively predicting, detecting, responding, and recovering from emergencies. 


\subsection{The Future Is Here: Technologies Being Used Today}

Since the birth of the Internet among defense agencies, great progress has been made in opening the technology to other agencies and the public. Three panelists representing law enforcement, transportation, and technology departments who use social media tools in their daily activities to communicate information on emergencies shared experiences and lessons learned. Panel members included:

- Bill Schrier, Chief Technology Office, City of Seattle (moderator)

- Sean Whitcomb, Sergeant of the Media Response Unit, Seattle Police Department

- Brian Kemper, Signal Operations and ITS Manager, Seattle Department of Transportation

Sergeant Sean Whitcomb of the Seattle Police Department explained how the agency came to use social media. In the past, they relied on newspapers and television, but the media landscape is changing rapidly. Through blogs, Twitter, and their own online police "blotter," they have become more proactive. Now, using social media tools allows them to reach the public without filtering information through the media and to build trust with people and the news media. Using social media has also save time; agencies can post information once and refer all inquiries to the same source. Some of the lessons they've learned include the following:

- People value speed over accuracy. People are more forgiving if information comes out quickly and is updated later than if it is withheld for verification purposes.

- Follow all rules and regulations when posting information online. Whitcomb and his colleagues follow standard procedures developed for talking to the news media.

- Branding is important; it helps the public know and trust the source of the information. Establishing the brand when things are slow will help when things turn hectic.

Brian Kemper of the Seattle Department of Transportation shared how "smart" transportation systems are being used extensively, such as in video from traffic cameras and remote ways to monitor traffic flow. In the future, parking availability will be provided via signage and online, to indicate the capacity of individual lots. Lessons they've learned include the following:

- If you build it, they will come. The department tracks how people find its information; over 80\% of visitors come through neighborhood-related blogs, indicating the viral spread of information in social media.

- Mobile access is becoming much more important. Especially for traffic information, people want data at their fingertips. Seattle is looking to have a third party make their web applications fully capable for all types of mobile devices for use by passengers.

Bill Schrier, Chief Technology Officer of the City of Seattle, provided links at www.seattle.gov/doit/notes.htm and noted new tools gaining acceptance across government agencies:

- Government social networking sites like www.govloop.com.

- Mashups that cross-correlate data among a variety of applications to give new insights

- $\quad$ RSS feeds ${ }^{5}$ and readers like Google Reader

\footnotetext{
${ }^{5}$ Format of web feed used to publish items that are frequently updated
} 
- Open data like that being made available through http://data.seattle.gov. The site is in its infancy but makes available data such as crime reports, licenses granted, and locations of public toilets for public use. Data like this has been used in other cities for public safety. 


\subsection{A View from the Trenches: Private Sector and Critical Service Provider's Perspective}

The private sector, especially organizations that provide critical services during emergencies, has unique needs and experiences in using social media. Three public information experts from critical service providers shared insights from their organizations. Panel members included:

- Davina Gruenstein, Public Relations Director, Puget Sound Energy

- Walter Neary, Public Relations Director, Comcast

- Lind Simonsen, Community Relations Coordinator, Pierce County Transit

- Sheri Badger, Public Information Officer, Pierce County Emergency Management (panel moderator)

\begin{abstract}
"The media landscape has changed drastically. We no longer have a reporter assigned to our specific beat where we are regularly in touch; now everyone is a reporter and a journalist because of social media.” Davina Gruenstein, Public Relations Director, Puget Sound Energy
\end{abstract}

Davina Gruenstein shared how Puget Sound Energy (PSE), a major provider of electricity and natural gas, uses social media heavily to connect with its customers. The company has a Wikipedia page, YouTube channel, LinkedIn account, blog, Facebook fan page, Twitter account, and Flickr account. PSE staff use the tools for two-way communications. For example, while they post their photos on Flickr for anyone to use, PSE hopes to include a gallery section where people could upload photos in an emergency to help provide situational awareness. PSE uses Twitter likewise to develop situational awareness. For example, last summer during a heat wave, they first identified outages via Twitter posts, which gave PSE an hour lead on the news media and allowed them be to more proactive in sharing information.

Lessons they’ve learned in applying social media include the following:

- Listen and listen some more. What are constituents saying? Where are they saying it?

- Learn from peers. Look at what similar organizations are doing and ask questions before going down the same path.

- Play, test, and review. Most social media tools cost nothing to try. See what works and pursue it.

- Create processes and expectations. People don't realize how highly public these web pages are; companies must build policies and awareness to protect reputation and manage brand.

- Actively engage your audiences. Posts to Twitter and other social media have to be routine and regular. It's a conversation.

Walter Neary explained that Comcast has learned they must be very agile in responding to customers because people have choices in where to get their entertainment. Company staff discovered by accident that they can use Twitter to respond to customer feedback. This change has been a huge step in social media and customer service. Another advantage to social media is that customers also help each other, not always waiting for the officials or administrators to reply to their questions. Forums are a good example of this form of crowd sourcing. While there is no substitute for a robust web site, which allows the company to control the message, companies also need a way to get information out quickly. Lessons learned include the following: 
- Start before the disaster. Joining social media early allows organizations to understand the format and be ready to use it in an emergency.

- Look for less constrained partners who may be able to speak on the organization's behalf during emergencies. During the Lakewood police shootings, the City of Lakewood said nothing until 24 hours after the incident; they were overwhelmed. Instead, a friend created a Facebook page to talk about the tragedy and gained over 70,000 followers, more than the 60,000 residents of Lakewood.

Lind Simonsen discussed how Pierce County Transit joined the social media conversation as a way to more effectively communicate with its customers after severe criticism from the media over lack of communication during an ice storm. However, when the community relations staff first proposed the idea, management didn't take it seriously. Management had to see a list of agencies that were already using social media and understand the ways it could help before they were willing to approve its use (see Appendix B). Because all Pierce County Transit buses are equipped with global positioning systems and two-way communications, information can flow directly into other media. The information is used, for example, to display standard route detours that are easily updated based on the circumstances. Lessons learned include the following:

- Even a government agency can moderate comments. Pierce County Transit’s Risk Manager had expressed concerns about potentially infringing on free speech. However, standard practice is to limit comments that could be offensive. Plainly state on the social media page the criteria for comments (no profanity, no attacks on others, etc.), and pull any posts that do not comply.

- Pages must be kept fresh every day. New information doesn't have to be specific to an organization's mission. For Pierce County Transit, it may be a tidbit about riding the bus, saving fuel, or changing schedules. If the organization staff have nothing new to say specific to busses, they mention community events.

Panelists also discussed the different skill sets that might be needed to effectively engage in social media. People in an organization often have three sets of skills: the ability to gather information (analysts), the ability to package and push information (public relations or communications), and the ability to dialog about pushed information. The last set of skills may be resident in other people in an organization, not necessarily in the public information department or among typical emergency responders. Knowing who has these skills may help identify individuals who can serve in emergencies and on a day-to-day basis.

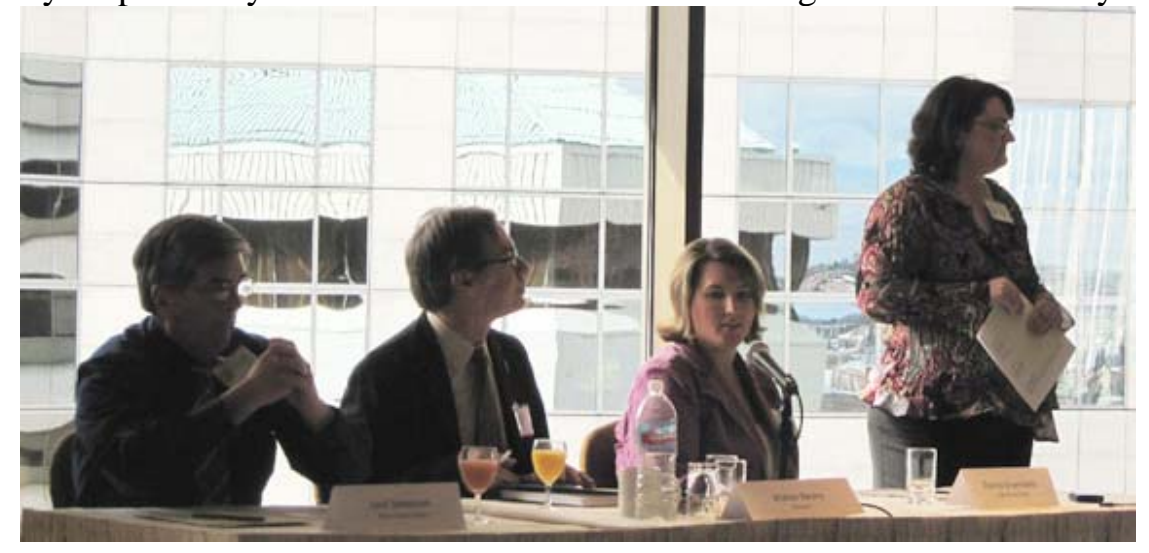

Panelist members left to right are: Lind Simonsen, Walter Neary, Davina Gruenstein, and Sheri Badger 
In addition, panelists agreed that social media is still largely for English-speakers. While many translation tools are available online, none is robust enough to rely on to accurately convey critical emergency information. Being able to translate into other languages in culturally acceptable ways often requires certified translators. Social media may also be more difficult if an organization's information technology staff are not prepared, funded, or skilled enough to assist. 


\subsection{More than Tracking Santa: How NORAD and NORTHCOM Use Social Media}

Another important player in emergencies is the military. Key speaker James Graybeal, Deputy Chief of Staff for Communications and Director of Public Affairs, North American Aerospace Defense Command (NORAD) and U.S. Northern Command (NORTHCOM), shared how the commands are using social media tools to reach out to their community and their country.

Once the Public Affairs Office at a military installation was focused on building and exercising relationships with national reporters. Now people consume information differently. They no longer look to major newspapers like The New York Times or traditional television news; they look to social media to direct them toward what they should read. One of the ways NORAD/NORTHCOM has responded is to hire a social media specialist. The Commander has a blog, and the commands have accounts on Twitter, Facebook, Flickr, and YouTube. They immediately update their social media pages before issuing a news release.

One strategy they are implementing is to enlist the 1,200 people working for the commands to sell their brand. In this model, the leadership focuses on communicating with workers, and the workers focus on communicating externally. An internal communication plan could help drive this kind of model. The commands hope that by building this initial network, a chain of communications can move from workers to the rest of the public and reach more people during a crisis.

"The $21^{\text {st }}$ century information chain has totally reversed the traditional chain of command." James Graybeal, Deputy Chief of Staff for Communications and Director of Public Affairs, NORAD/USNORTHCOM

The commands recognize that social media is a grass roots effort. An organization may end up beginning a dialog with people who don't like it. If an organization takes on every negative comment, however, it loses. The information that seems to resonate most with NORAD/NORTHCOM followers include:

- Information about their people

- Missions and events they are doing (Haiti earthquake for example)

- 9/11 events — still

- Major national and world events such as the Super Bowl and the Vancouver 2010 Olympics.

One of their most popular pages is the Santa Tracker. This year, they tied it to their social media network. The impact was enormous: they raised their fan base $766 \%$ in one month, with inquiries from as far away as North Korea and Germany. They are working to leverage this fan base across their other information vehicles.

James Graybeal cautioned against having too many reviews before posting information. When the Department of Homeland Security identifies an emergency, leaders generally gather communication staff from the Federal Emergency Management Agency, the White House, USNORTHCOM, and state emergency response organizations on a conference call to align messages. While everyone is talking, each person is updating Facebook and other social media sites in real time. This kind of response separates the chain of command from the information chain.

The commands hope to increase fans and followers, awareness of the missions, and agency partners for cross communication. They want to be the site for military emergency information. 


\subsection{Tools to Use: Existing Models and Best Practices}

The use of social media may be relatively new for emergency management, but a number of agencies are currently using the tools to great effect. A panel of city and private sector social media users described experiences and offered best practices to use today. Speakers included:

- $\quad$ Leng Caloh, Convergence Editor, KPBS San Diego

- Joe Spurr, Web Developer, KPBS San Diego

- Sabra Schneider, Web Master, King County

- Edward Vassallo, Ready Coordinator, City of Philadelphia (via Skype)

- Laurie Van Leuven, Strategic Advisor and Manager, Seattle Public Utilities (panel moderator)

Leng Caloh and Joe Spurr lived through the 2007 California wildfires. At the time, government agencies were using traditional means to communicate: press releases, media briefings, information hotlines, and the like. The disaster consumed all traditional media outlets in California and strained existing information systems. The citizens were frustrated. KPBS staff hoped to help the community understand and respond more effectively to the emergency. They created a Google map with evacuation centers, road closures, and borders of the fire. Part of the reason KPBS used Google was because their own servers were overwhelmed, and they couldn't access their own site. Google agreed to host the map and even put on extra workers when its servers started becoming overwhelmed. This is one of those instances where partnering with private industry was critical. Even government agencies were linking to their site.

"Give people the information. Let them make decisions. Let them contribute." Leng Caloh, Convergence Editor, KPBS San Diego
Suggestions for best practices include the following:

- Forget sending news releases as PDFs. They clog systems, take too long to access, and offer inaccessible data. Instead, offer opportunities to subscribe to RSS feeds.

- Make people available to answer questions. A spokesperson may need to answer questions from the public, but private sector partners need information on interpreting data. Provide more opportunities for open access to the emergency operations center staff.

- Take advantage of the new volunteerism. Information technology experts, software developers, and computer programers are banding together online through Crisis Camps to aid major disasters. In addition, volunteers can develop more accurate maps through OpenStreetMap, as was done recently after the Haiti earthquake.

- Trust the public's ability to make sense of information and to contribute to the community's understanding of crisis. Today, more data are better than less.

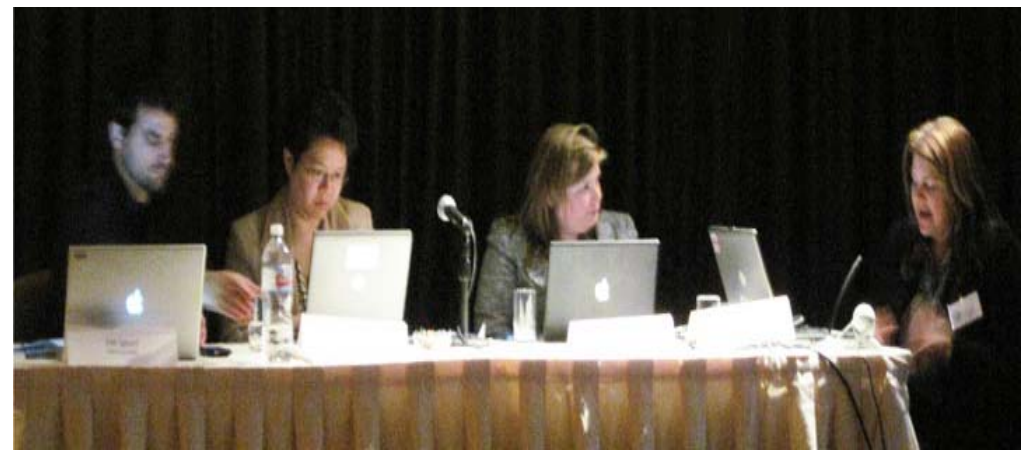

Panel members left to right are: Joe Spurr, Leng Caloh, Sabra Schneider, and Laurie Van Leuven 
Sabra Schneider shared how King County built a dynamic web page. The Public Information Office realizes, however, that they cannot release information on a news cycle that no longer exists. They must be able to communicate in all four stages of an emergency: mitigation, preparedness, response, and recovery. Suggestions for best practices include the following:

- Establish a presence before the emergency. In Hurricane Ike, the most recognizable voice was the news media. Where was the government information? An agency needs to have established a voice, credibility, and connection with the public before a crisis.

"There's no sleeping in a crisis." Sabra Schneider, Web Master, King County

- Identify partners who can help in emergencies. King County has identified people who will work with social media to staff the Joint Information Center under the media team during an emergency.

- Be timely. The public expects up-to-the-minute information, and they will turn elsewhere if they don't get it. Ten levels of approval that result in delays won't work.

- Remember that social media targets the most engaged and "wired" citizens. To reach everyone in an emergency, you also need to communicate through more traditional channels.

Edward Vassallo joined the workshop via Skype and discussed how the City of Philadelphia's emergency management agency has an active social media program. They work hard to establish a two-way dialog, to engage citizens. For example, during the recent snow emergency, they improved situational awareness by looking at pictures people had shared from train stations. They also alerted people to the activation of the emergency operations center during a transit strike. Suggestions for best practices include the following:

- Update continuously. To make sure they always have updated information, they even post information about job openings and conferences.

- Cross train. Edward Vassallo trained everyone in the office to use social media so people can help during emergencies.

Laurie Van Leuvan stressed that information needs during an emergency skyrocket. People consume information and data at a very rapid pace. This kind of engagement forms an active coping mechanism to help toward recovery. Four technologies that appear to be especially useful for emergency management are wikis, blogs, Twitter, and applications built from mashups ${ }^{6}$.

Speakers shared some of the issues associated with social media. Some agencies fear that misinformation will spread. KPBS staff have found that their large audience is faster at digestion. If a mistake is made, they admit and correct it. Because of the "wisdom of the crowd" inherent in most social media applications, problems like these are often self-correcting. In Philadelphia, someone mistakenly posted that the emergency management office was closing in an emergency. The office quickly corrected the information.

A participant wondered if there would be a clash between the hierarchical incident command system and the more viral social media. Panelists suggested looking to the U.S. Forest Service's use of social media in emergencies as an example of how the two systems can be integrated.

\footnotetext{
${ }^{6}$ A web page or application that uses and combines data, presentation or functionality from two or more sources to create new services.
} 


\subsection{Conclusions}

Social media tools can help communicate with the public in emergencies, build situational awareness, and spur recovery. The presentations and participant discussions led to several conclusions:

- Agencies have to trust the public on some level to manage emergencies. All emergencies are local, and public.

- More needs to be studied in regards to how crowd sourcing leads to robust decisions. Experts in general tend to struggle with the concept that people are turning more and more online to a fan base to help guide their decisions.

- Deferring the release of information is no longer option. Using social media tools can be done; it is being done and done well in the emergency management community. However, agencies must consider the ramifications (staffing, resources, control of information) when joining the social media conversation.

- Public demand and competition, even among government agencies, will drive the data. One city cannot afford to remain silent when others are openly sharing.

- People want information, and they expect it immediately. The challenge will be balancing resources and accuracy against the need to produce instant information.

- Government agencies may have to change policies, practices, and skill sets to effectively use social media. They will need to use new terms like branding and dialog. They may also need to partner more broadly.

- Organizations must identify the objective for using social media. Knowing what the organization hopes to achieve guides the use of tools.

"How do we know what success
is? How do we measure it?
How do we know when we've
arrived?" Glen Woodbury,
Director, Center for Homeland
Defense and Security, Naval
Postgraduate School

One of the ways to help build advocacy for the use of social media is to identify champions. Agencies need a strategy and the right person to engage the right stakeholders to develop a model that can be used as an example to build tools that engage communities. A key component of this strategy will be the ability to analyze the tremendous amount of information coming out of social media and the use of crowdsourcing.

Social media is a new frontier for emergency management. This workshop was a step in learning where and how to take advantage of such tools to safeguard communities and help them recover from crises.

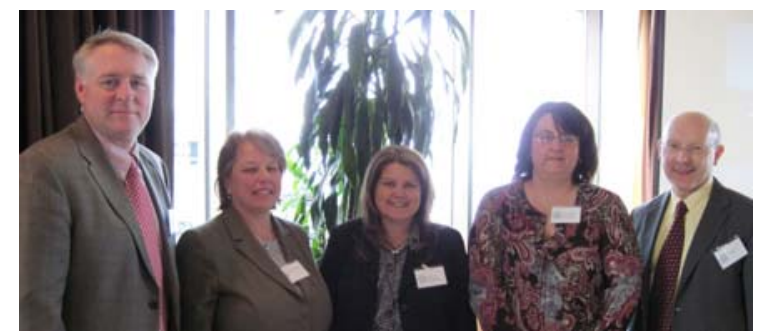

Keynote speaker Glen Woodbury with workshop organizers Ann Lesperance, Laurie Van Leuven, Sheri Badger, and Bill Schrier 


\title{
Appendix A Agenda
}

\section{Social Networking for Emergency Management and Public Safety}

\author{
Wednesday, March 10, 2010 \\ 8:00 am - 4:00 pm \\ Sheraton Hotel, Seattle, WA
}

\section{AGENDA}

\begin{abstract}
TIME TOPIC
8:00 - 9:00am Registration and Breakfast

9:00am Opening Remarks - Welcome and Introduction

Ann Lesperance, Deputy Director, Northwest Regional Technology Center, Pacific Northwest National Laboratory
\end{abstract}

9:20am

To Tweet, or Not to Tweet: That is the Question for Public Safety Leaders in the $21^{\text {st }}$ Century

Glen Woodbury, Director, Center for Homeland Defense and Security

Naval Postgraduate School

10:00am Technology Demonstrations

Moderator: Bill Schrier, Chief Technology Officer, City of Seattle

- Sean Whitcomb, Sergeant of the Media Response Unit, Seattle Police Dept.

- Brian Kemper, Signal Operations and ITS Manager, Seattle Dept. of Transportation

- Bill Schrier, City of Seattle

11:00am Break

11:15am Private Sector and Critical Service Provider's Perspective Moderator: Sheri Badger, Public Information Officer, Pierce County Emergency Management

- Davina Gruenstein, Public Relations Director, Puget Sound Energy

- Walter Neary, Public Relations Director, Comcast

- Lind Simonsen, Community Relations Coordinator, Pierce County Transit

12:30pm Lunch 
$1: 15 p m$

NORAD and NORTHCOM Social Networking

James Graybeal, Deputy Chief of Staff for Communications, and Director of Public Affairs NORAD and US Northern Command

Existing Models and Best Practices of Social Networking Tools Moderator: Laurie Van Leuven, Strategic Advisor and Manager, Seattle Public Utilities

- Leng Caloh, Convergence Editor, KPBS

- Joe Spurr, Web Developer, KPBS

- Sabra Schneider, Web Master, King County

- Edward Vassallo, Ready Coordinator, City of Philadelphia 


\section{Appendix B Presentations and Handouts}

B-1 Glen Woodbury, Director, Center for Homeland Defense and Security Naval Postgraduate School
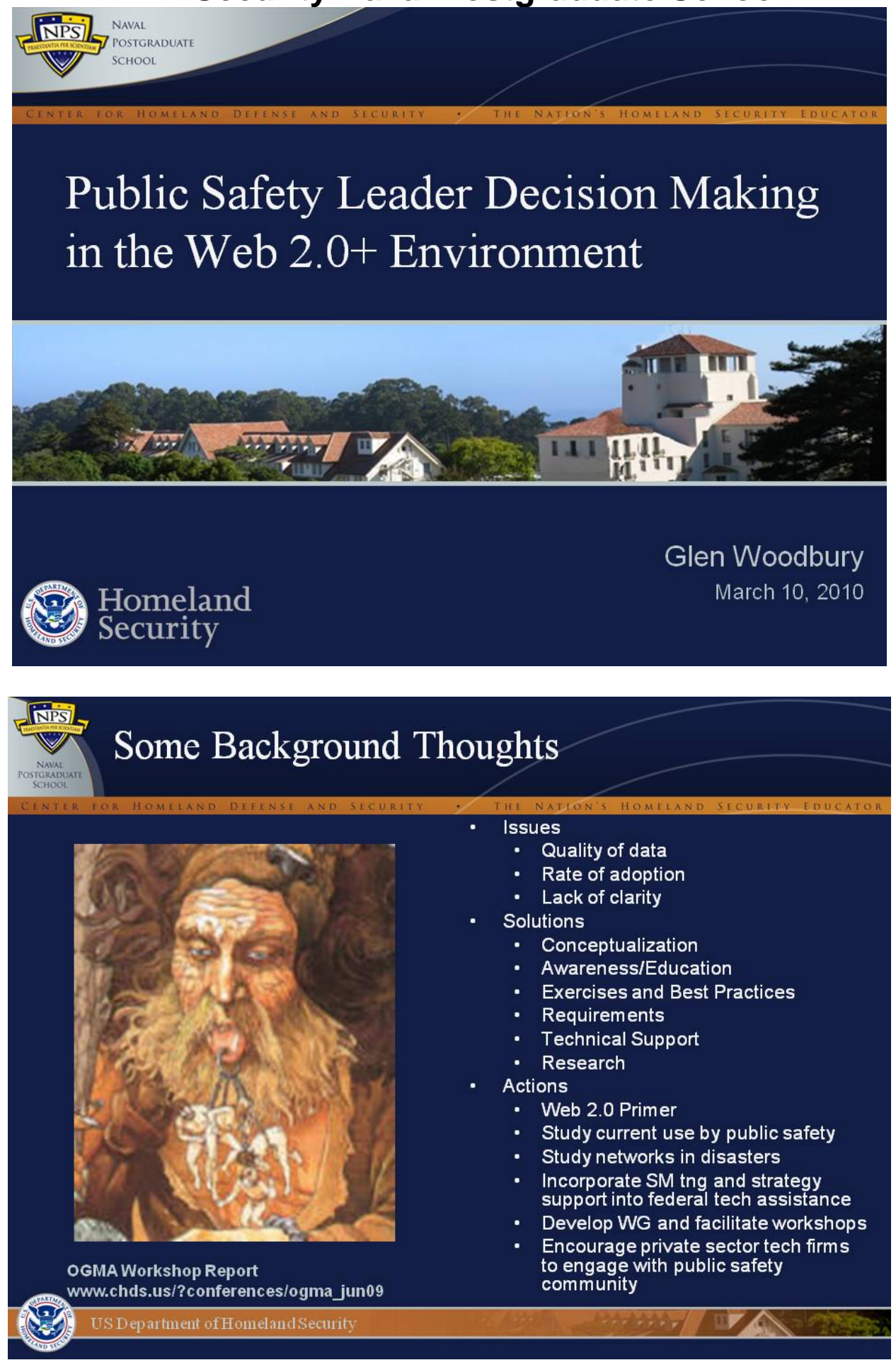

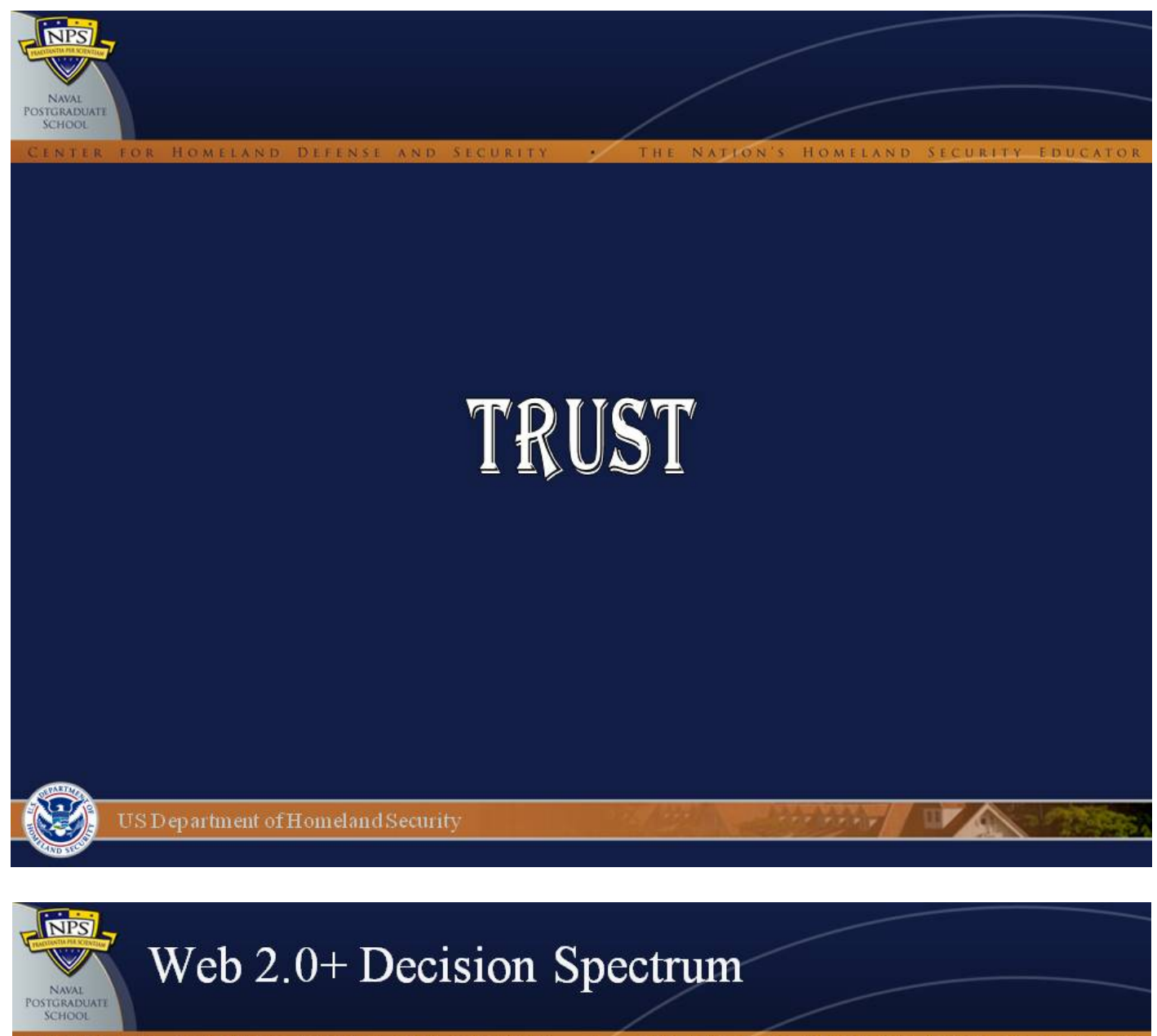

CENTER FOR HOMELAND DEFENSE AND SECURITY. THE NATHON'S HOMELAND SECURITY EDUCATOR
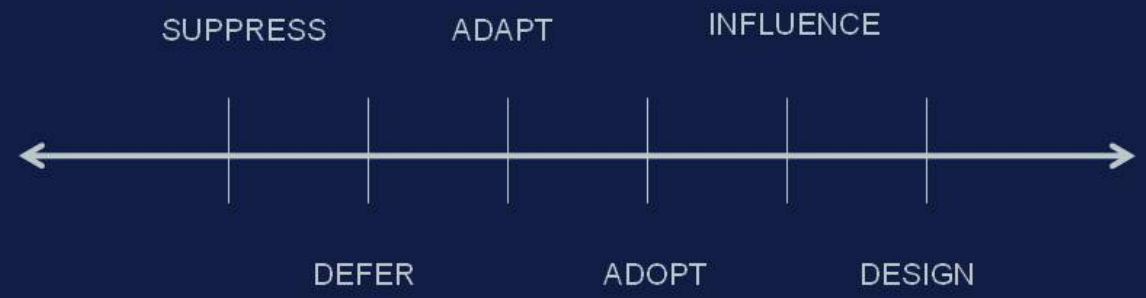

Decision-makers have options along the spectrum above in regards to how they might handle web 2.0 (or $3.0,4.0$, etc.) technologies and tools. 


\section{Web 2.0+ Decision Spectrum}
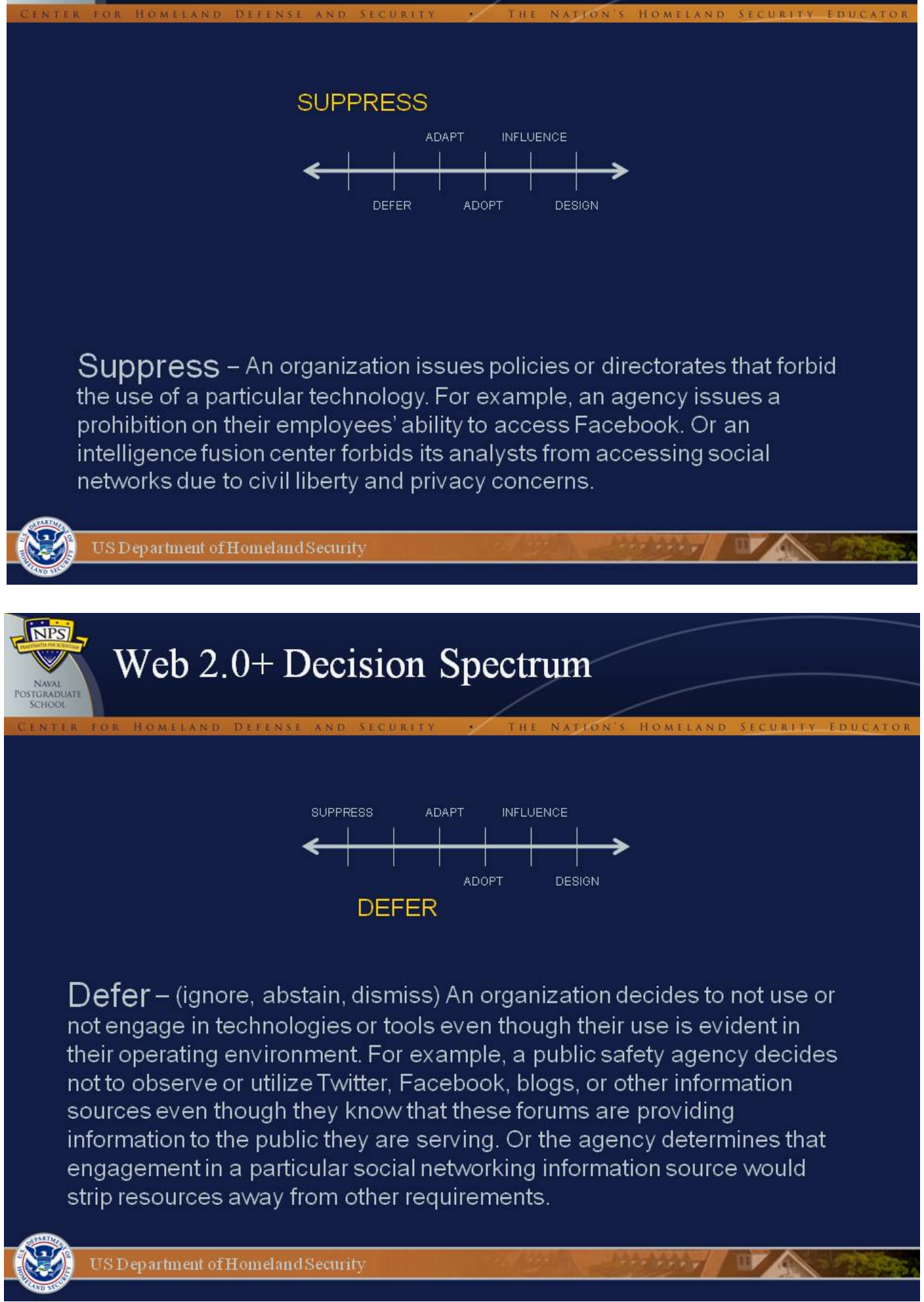


\section{Web 2.0+ Decision Spectrum}

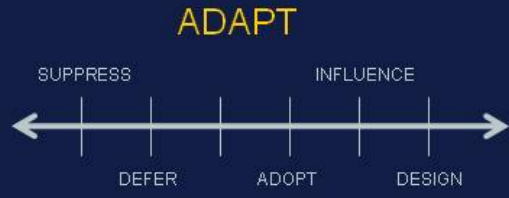

Adapt (Reactive) - An organization observes the use of technologies and tools in their environment and decides to adjust its policies and procedures in order to participate in the same technological environment. For example, a fire agency discovers that the public is relying or acting on information from Twitter sources, so it decides to enter Twitter forums and generate its own content.

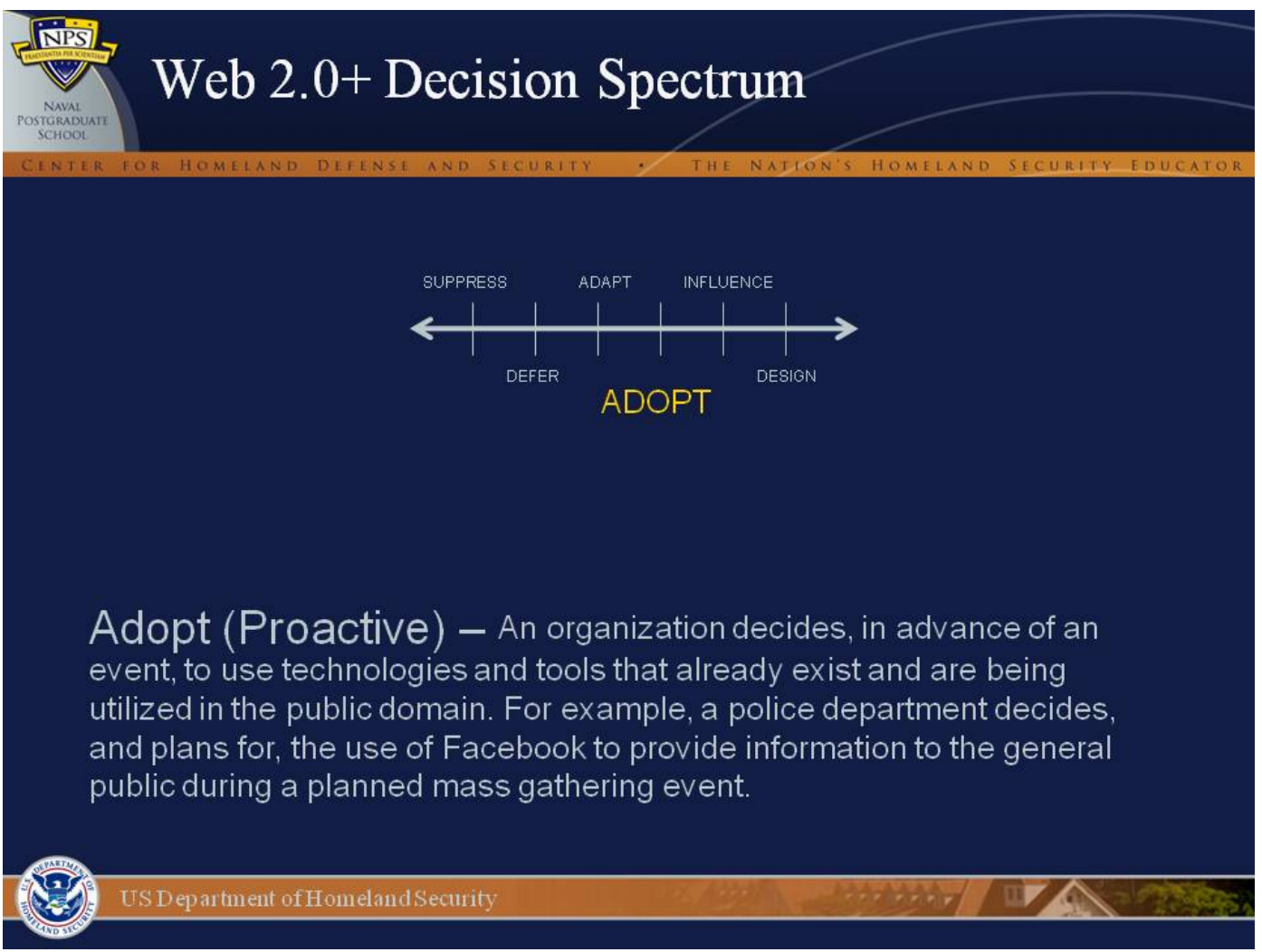




\section{Web 2.0+ Decision Spectrum}
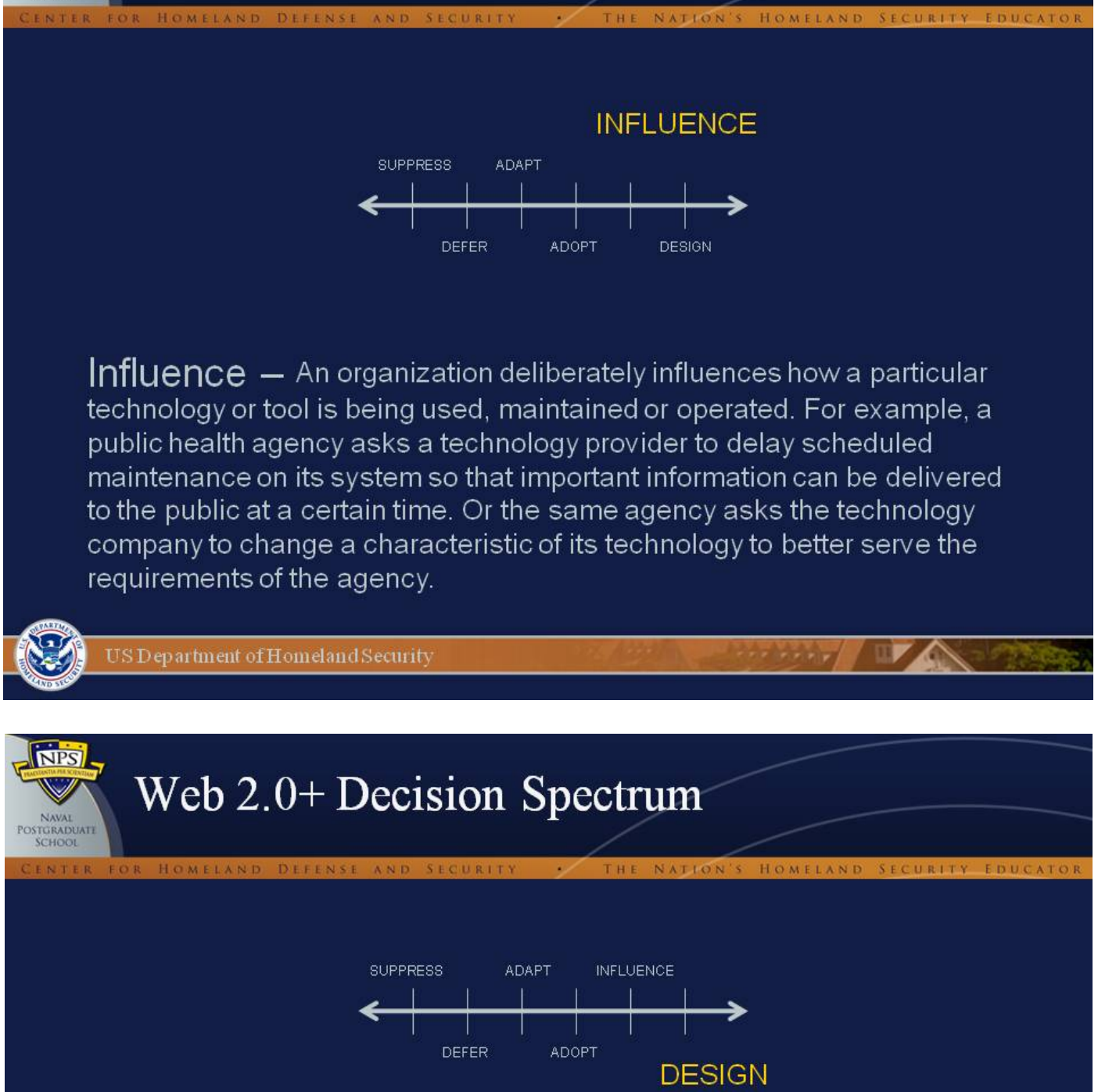

Design - An organization determines requirements that might be served by new technologies and tools and seeks a design and production of a system to serve those needs. For example, an emergency management agency desires a new way to hold collaborative planning discussions in a virtual environment and engages with a technology provider to build the product. 


\section{Is this essentially just about "information"?}

In a crisis, "you must treat information as a commodity as important as the more traditional and tangible commodities such as food, water, and shelter."

DHS Deputy Secretary Jane Hull Lute - March 8, 2010

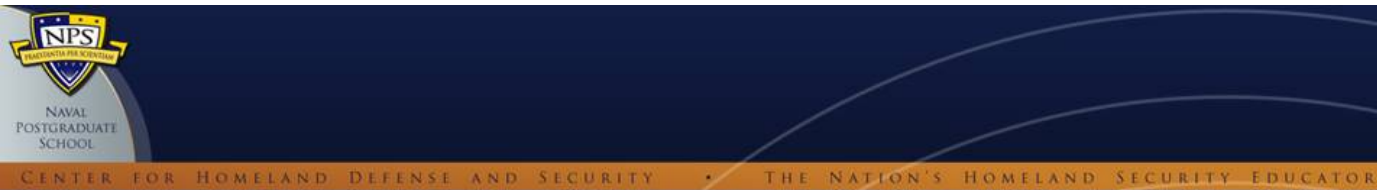

Glen Woodbury

Director

Center for Homeland Defense and Security

Naval Postgraduate School

glwoodbu@nps.edu

(831)656-3038

www.chds.us 


\section{B-2 Lind Simonsen, Community Relations Coordinator, Pierce County Transit}

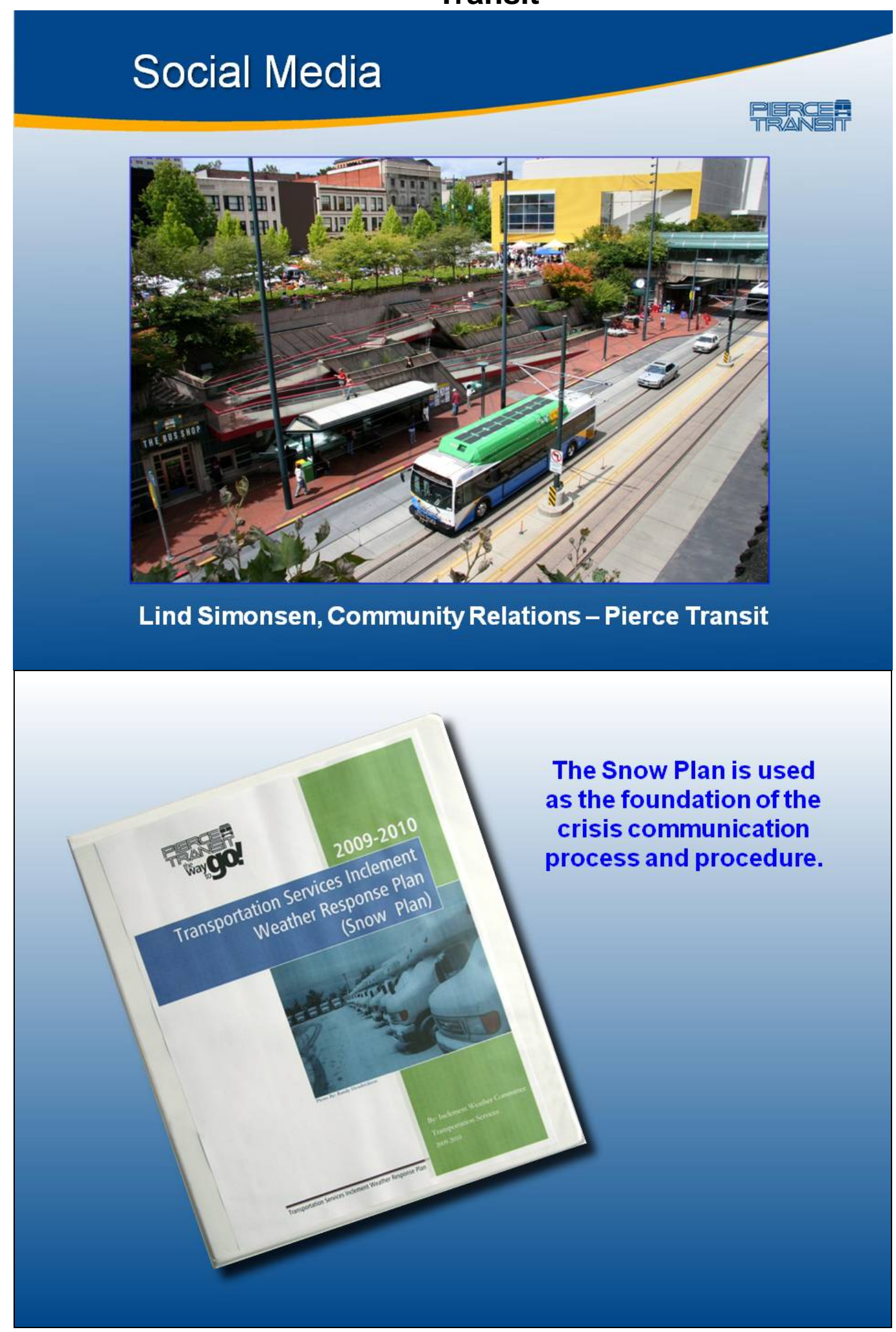



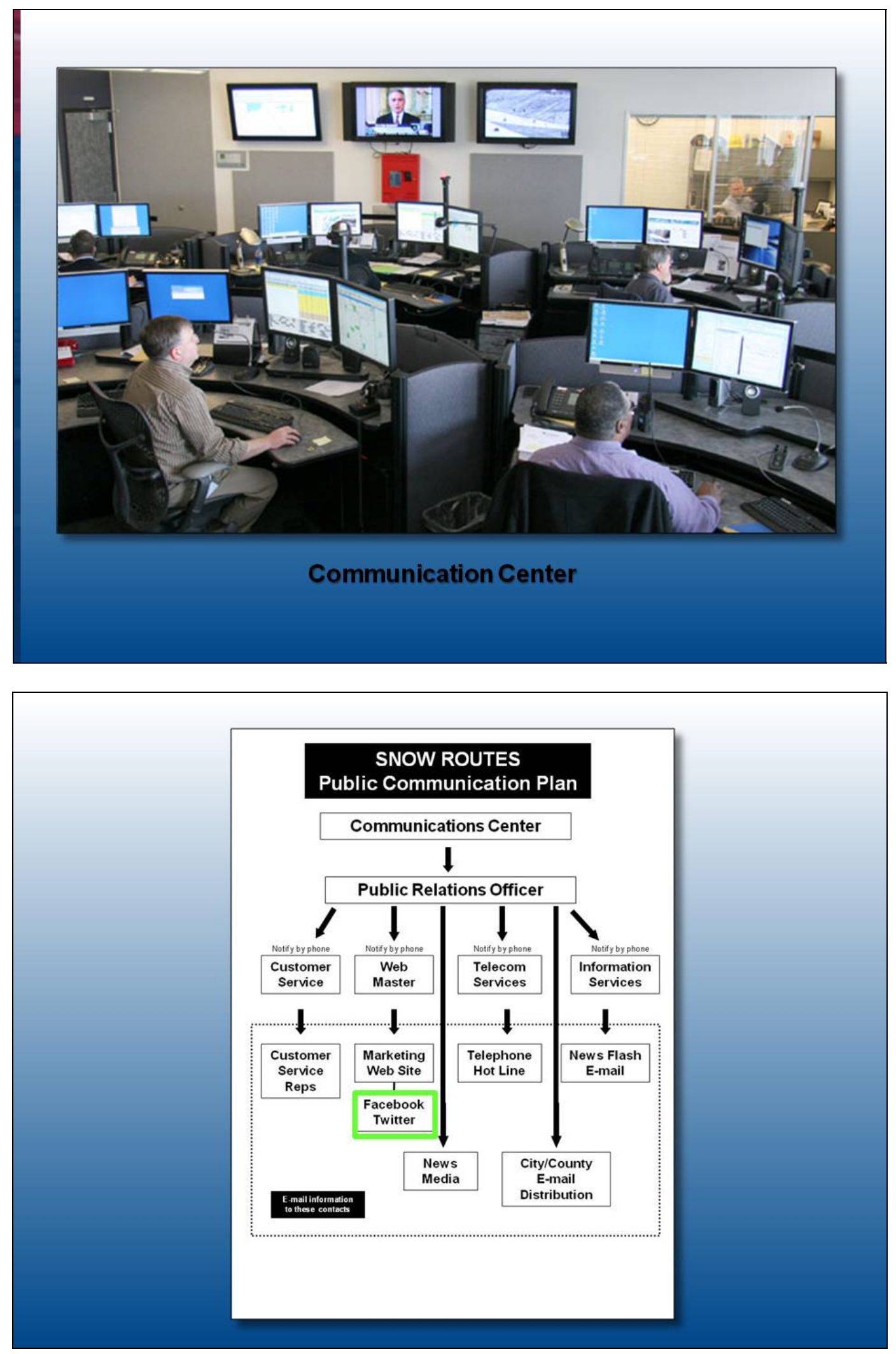

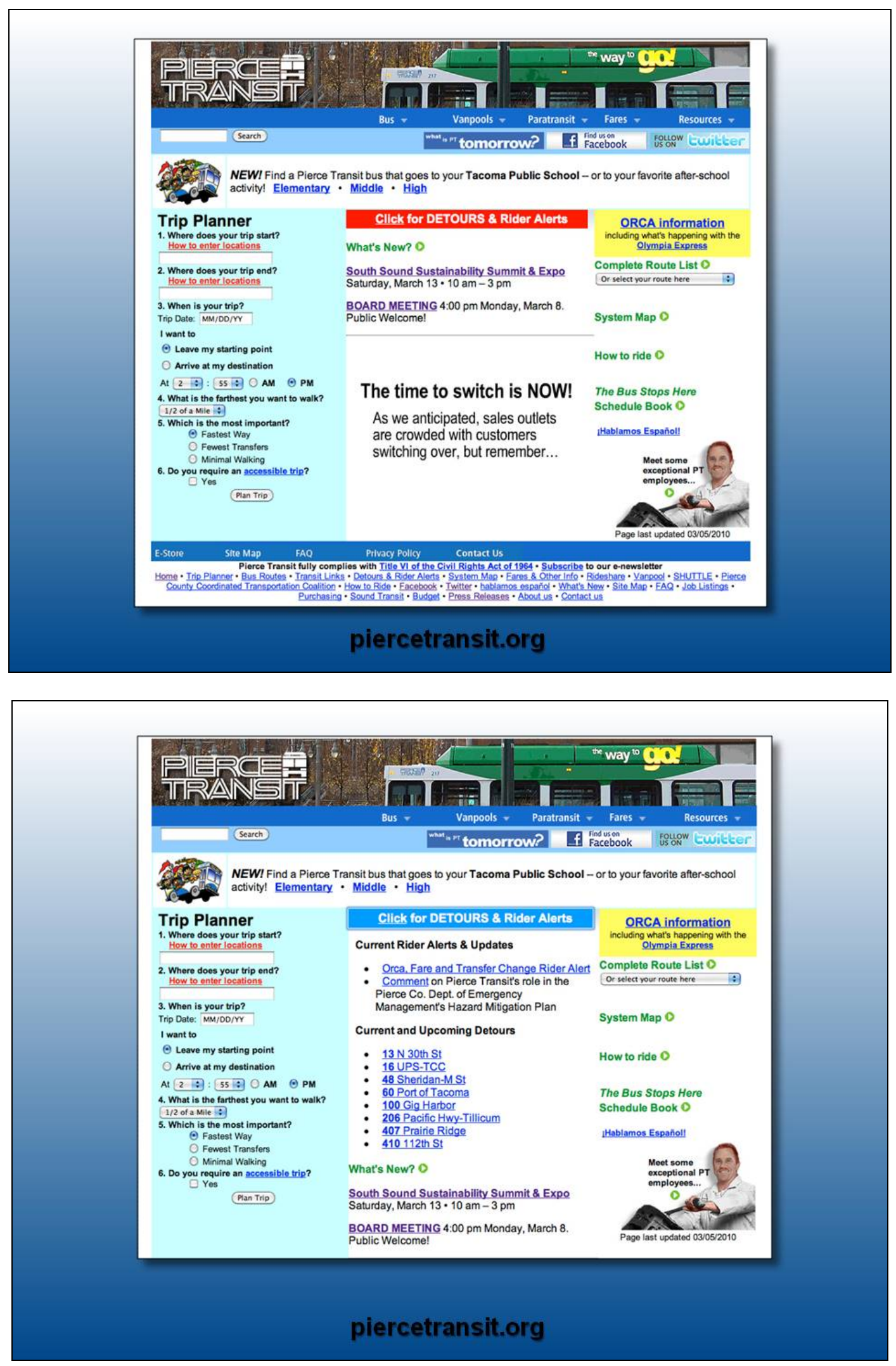

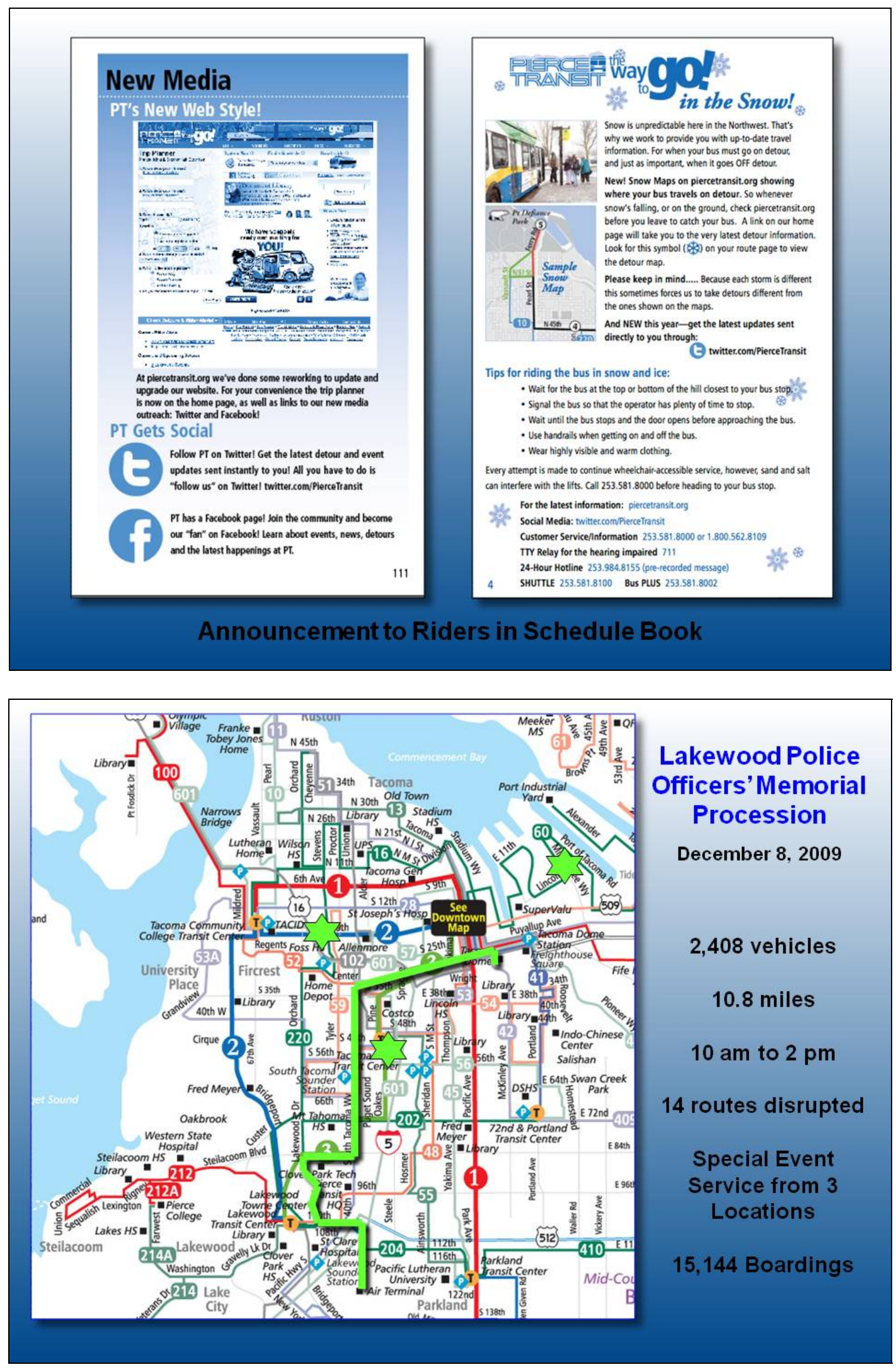
PRESS RELEASE: Procession for slain officers will impact bus service. Pierce Transit is rerouting buses around the... http://bit.ly/5ntDSx

4:31 PM Dec 4th, 2009 via Facebook

All bus service will be impacted on Tuesday due to procession, congestion around Tacoma Dome. PT is offereing... http://bit.ly/8R3mdd

9:10 AM Dec 4th, 2009 via Facebook

Lakewood Officer Memorial: Pierce Transit is rerouting buses around the procession. If your Tuesday travel plans... http://bit.ly/90HXrh

9:08 AM Dec 7th, 2009 via Facebook

\section{Advanced Notice}

\section{twitter}

Pierce Transit Bus service will be delayed today due to the

Memorial Procession. For the latest information on route detours

check PT's website. Information and map is also included for procession.

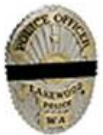

Lakewood Police Officers Memorial

unw.piercetransit.org

Service begins at 10:30 am; last bus leaves each site for the Dome at noon. Return buses will be available immediately after service ends.

क] December 8, 2009 at 8:56am - Comment - Like - Share

\section{Early Announcement}

facebook

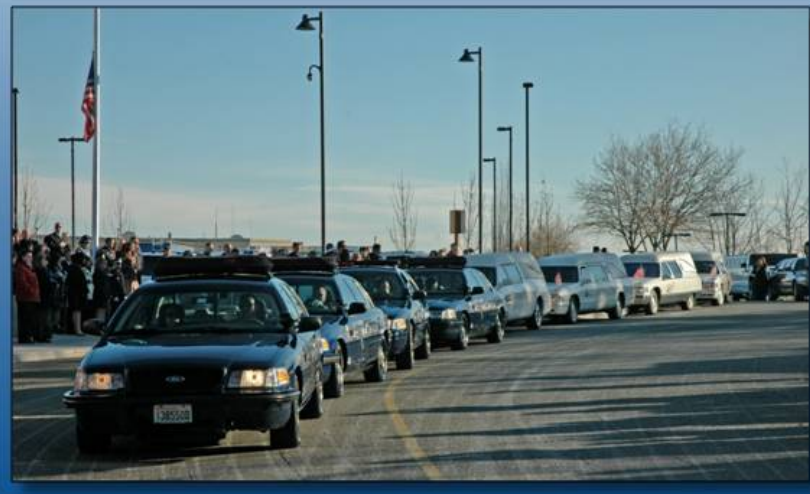


Bus service will be delayed today due to the Memorial

Procession. For the latest information on route detours

check... http://bit.ly/5E3TbB

8:56 AM Dec 8th, 2009 via Facebook

Routes $603,594,574,204,48$ are all back to regular route since the procession is almost complete. http://bit.ly/8iSAQr 1:56 PM Dec 8th, 2009 via Facebook

CONGESTION AT THE TACOMA DOME AND ON SURROUNDINC STREETS CONTINUES TO BE SEVERE, AND WILL WORSEN

DRAMATICALLY WHEN... http://bit.ly/4WhrUW

2:21 PM Dec 8th, 2009 via Facebook

\section{Procession Status}

\section{twitter}

Pierce Transit 42 is ON DETOUR for the Lakewood Police Officers memorial service at the Tacoma Dome

Route 42

unw. piercetransit.org

HOWEVER, CONGESTION AT THE TACOMA DOME AND ON SURROUNDINC

STREETS CONTINUES TO BE SEVERE, AND WILL WORSEN DRAMATICALLY WHEN

THE SERVICE IS OVER AROUND 5:00 PM. Expect your ride to take much longer

than usual, and keep in mind that many connections between buses WILL be missed.

6] December 8, 2009 at 2:47pm . Comment - Like - Share

\section{Afternoon Announcement}

facebook

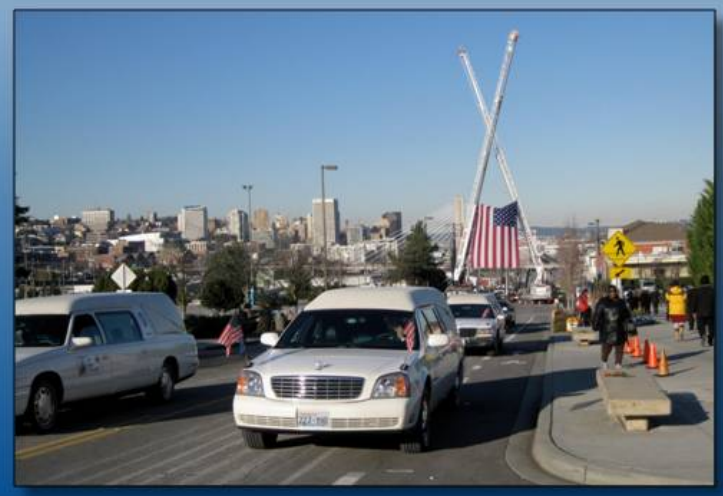



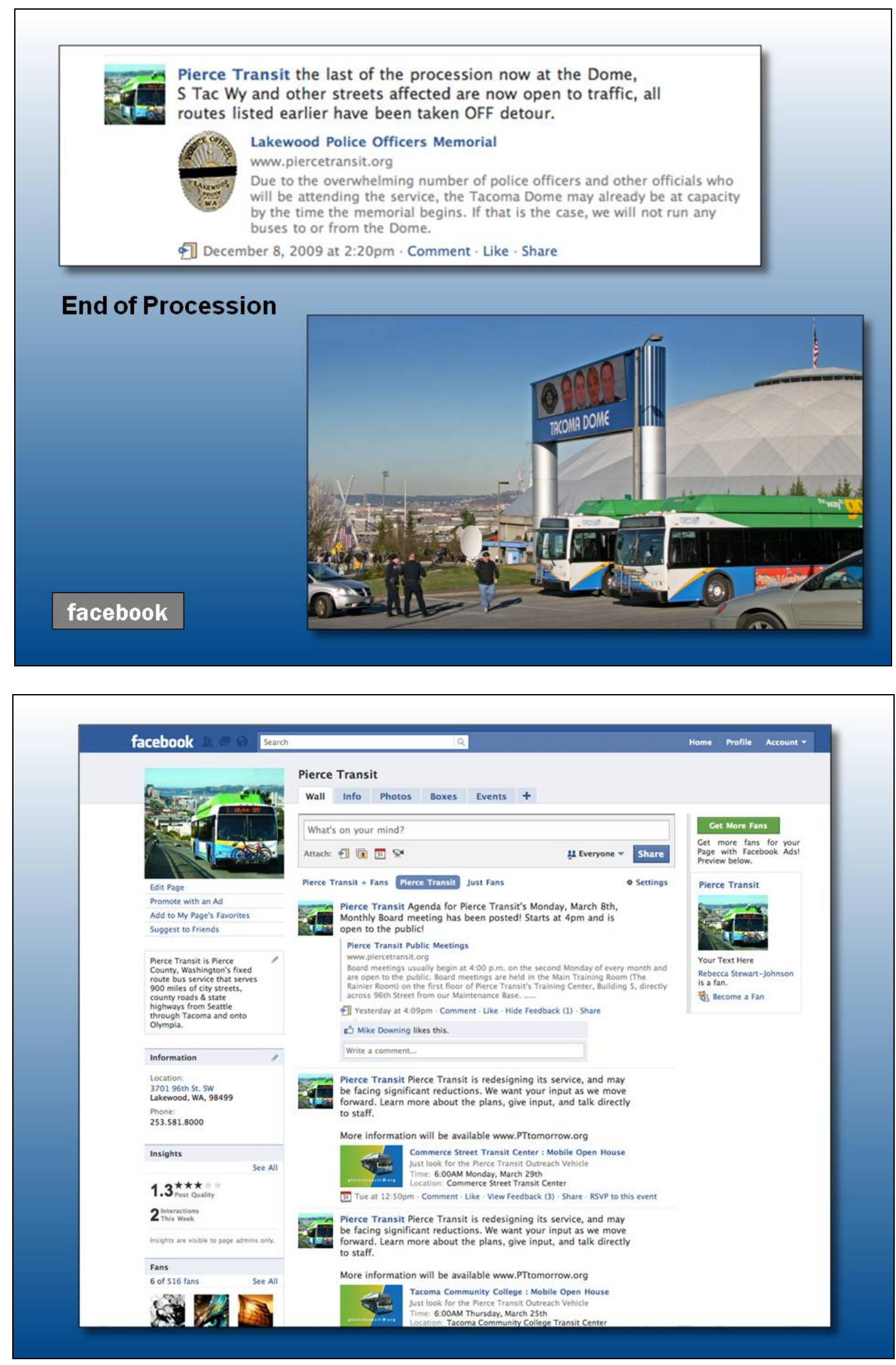

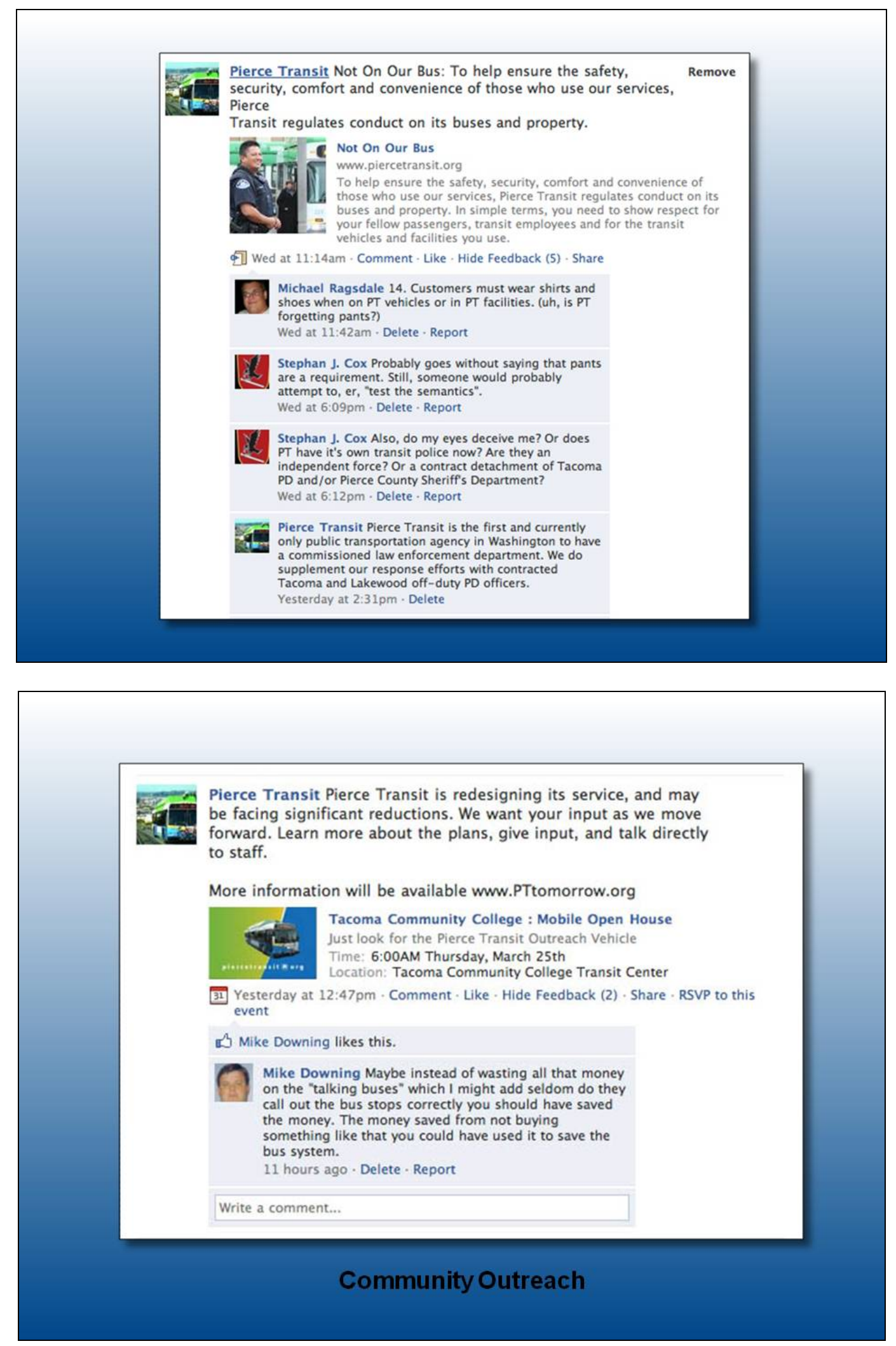

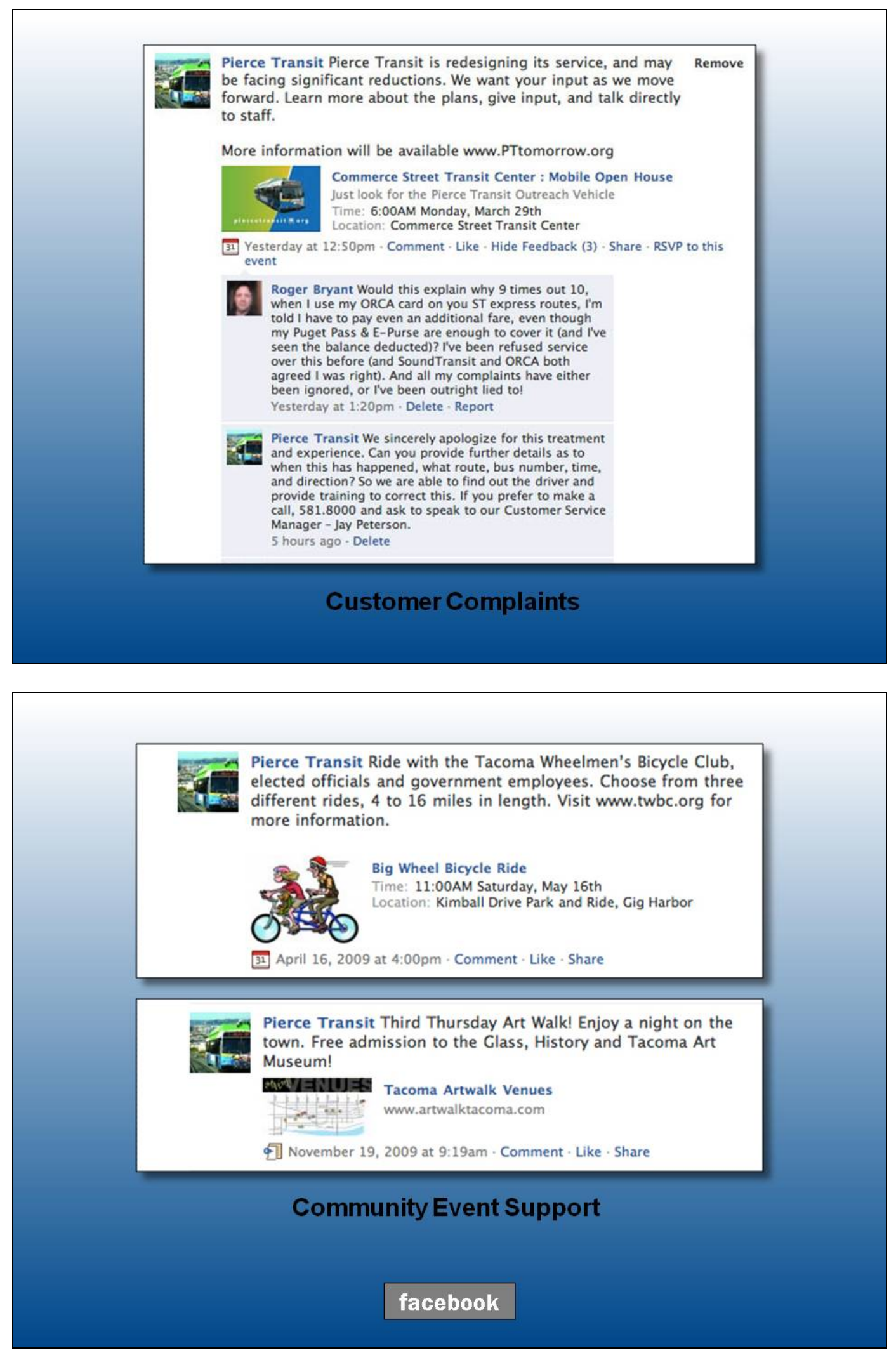

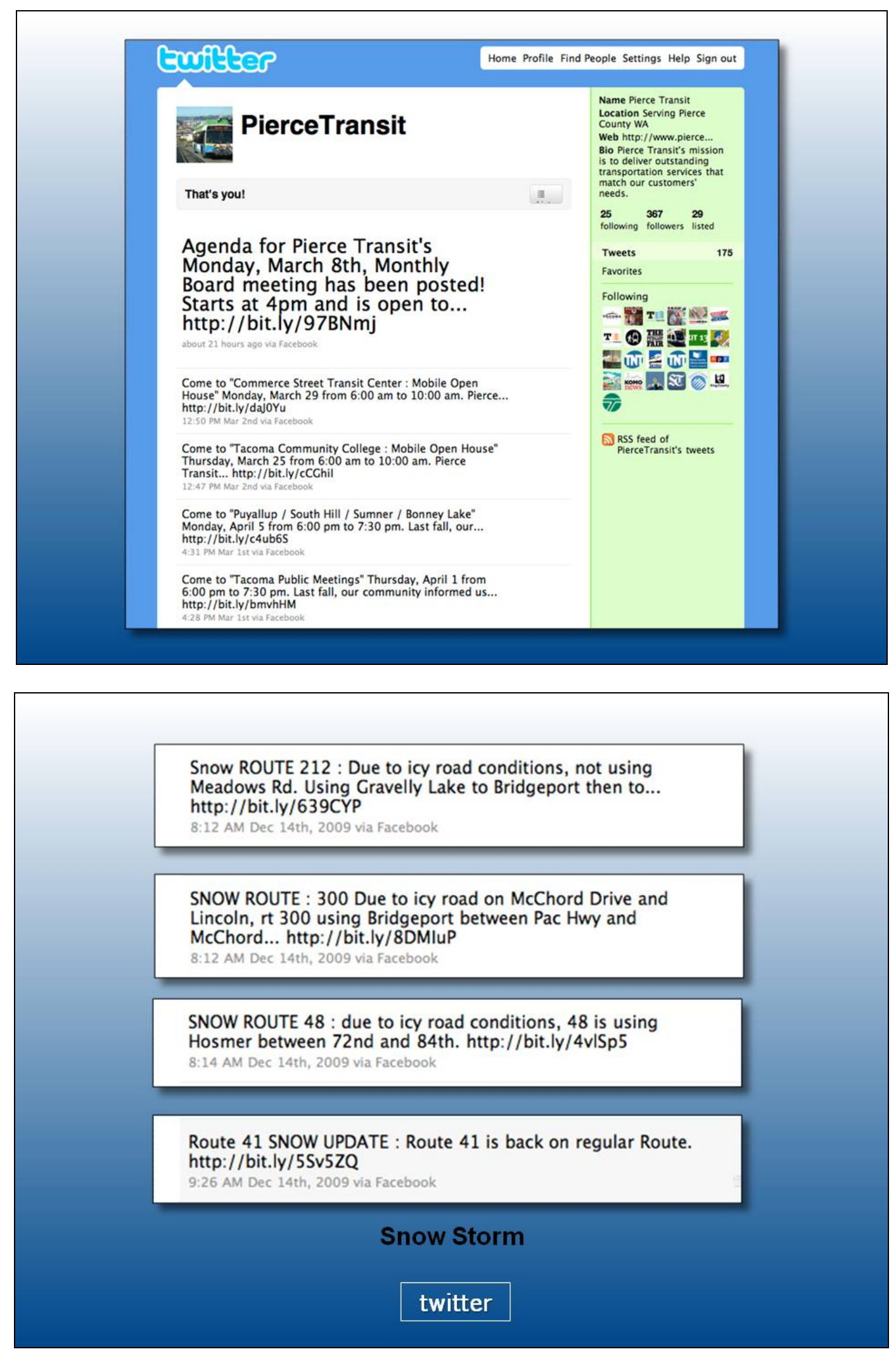


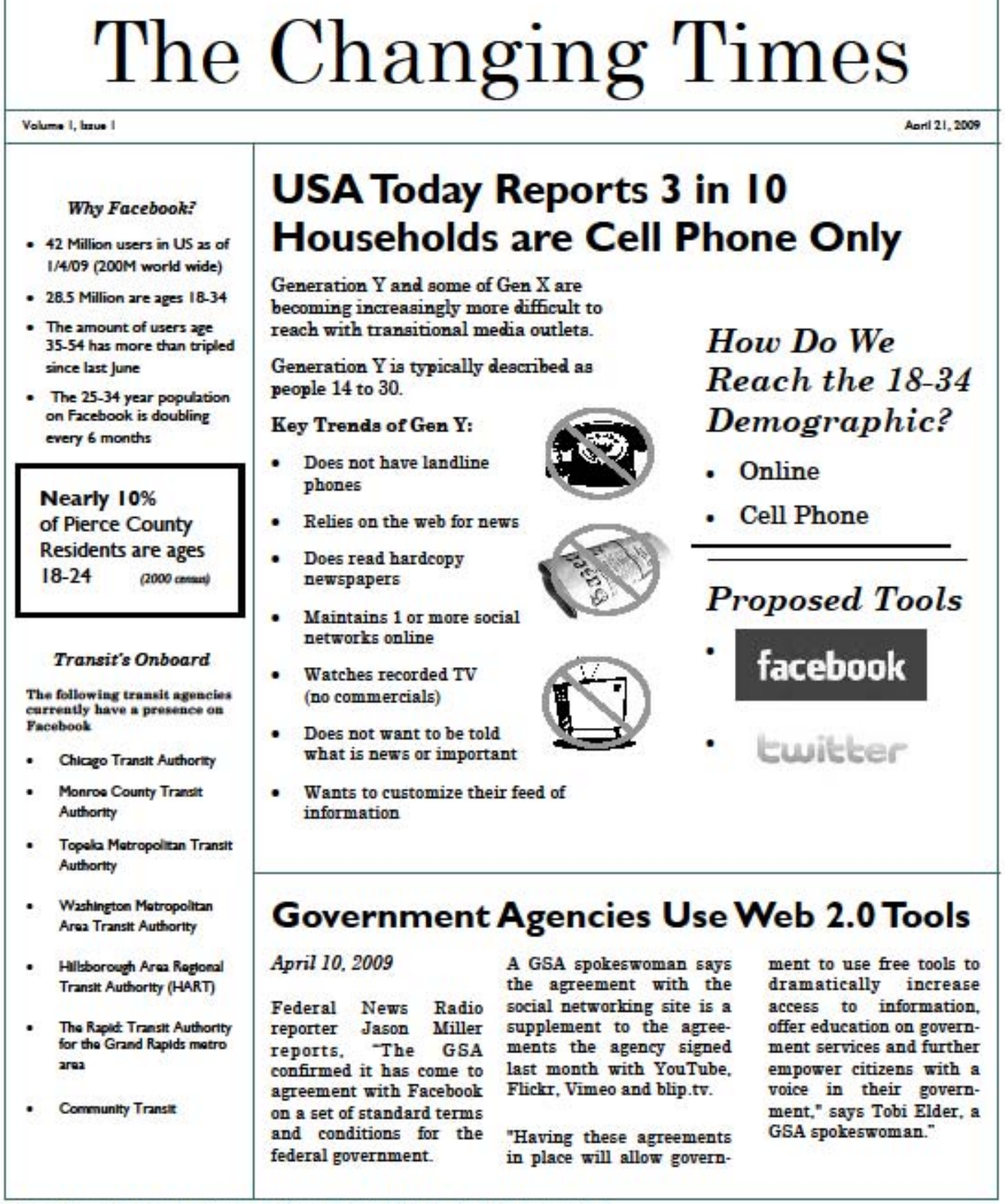

Pierce Transit Leadership Team Meeting Handout 4/21/09-New Media Outreach 



\section{Tips for Creating Facebook Pages}

\section{Sell it!}

Tip 1: Communicate benefits to senior leadership - Low cost (labor only)

- Reach hundreds of "fans" with a single post

- Target a new demographic

- Communicate instantly about

changes and emergencies

- Create a dialogue with your

online community

Tip 2: Resolve policy issues

- Who can post?

- Can employees view at work?

- Who decides on content?

- Are discussions allowed?

\section{Iip 3: Achieve buy-in}

- Formal anoroval or nroceed with

site design

- Be sure to keen Customer Senvice

in the loop so comments are

hand ded appiogiately

\section{Build it!}

Tip 1: Decided on your Facebook strategy

- Community focus

- Feedback mechanism

- Agency news

- Employee communication

- Alerts and updates

Tip 2: Prep for the page

- Sign up for a Facebook page

- Designate Admins for the page

Iip 3: Select content and photos

- Post selected photos to

Photobucket.com account

- Revise content to use a more casual

tone if borrowing from other agency sources

Tip 4: Create page tabs using FBML

Iip 5: Add "Page Fayorites" box

\section{Maintain it!}

Tip 1: Strive to post 1 update a day

Ideas indude:

- Links to a new news article or video clip

- Information about a community event

- Invitation to an organization's event

or meeting

- Fun facts

Tip 2: Respond to questions in a timely manner to show fans you are engaged

IIp 3: Keep the tone casual and appropriate

Iip 4: check the stats

- New fans

- Lost fans

- Demographis of fains

- Interaction with the page 
B-3 James Graybeal, Deputy Chief of Staff for Communications and Director of Public Affairs, NORAD and US Northern Command

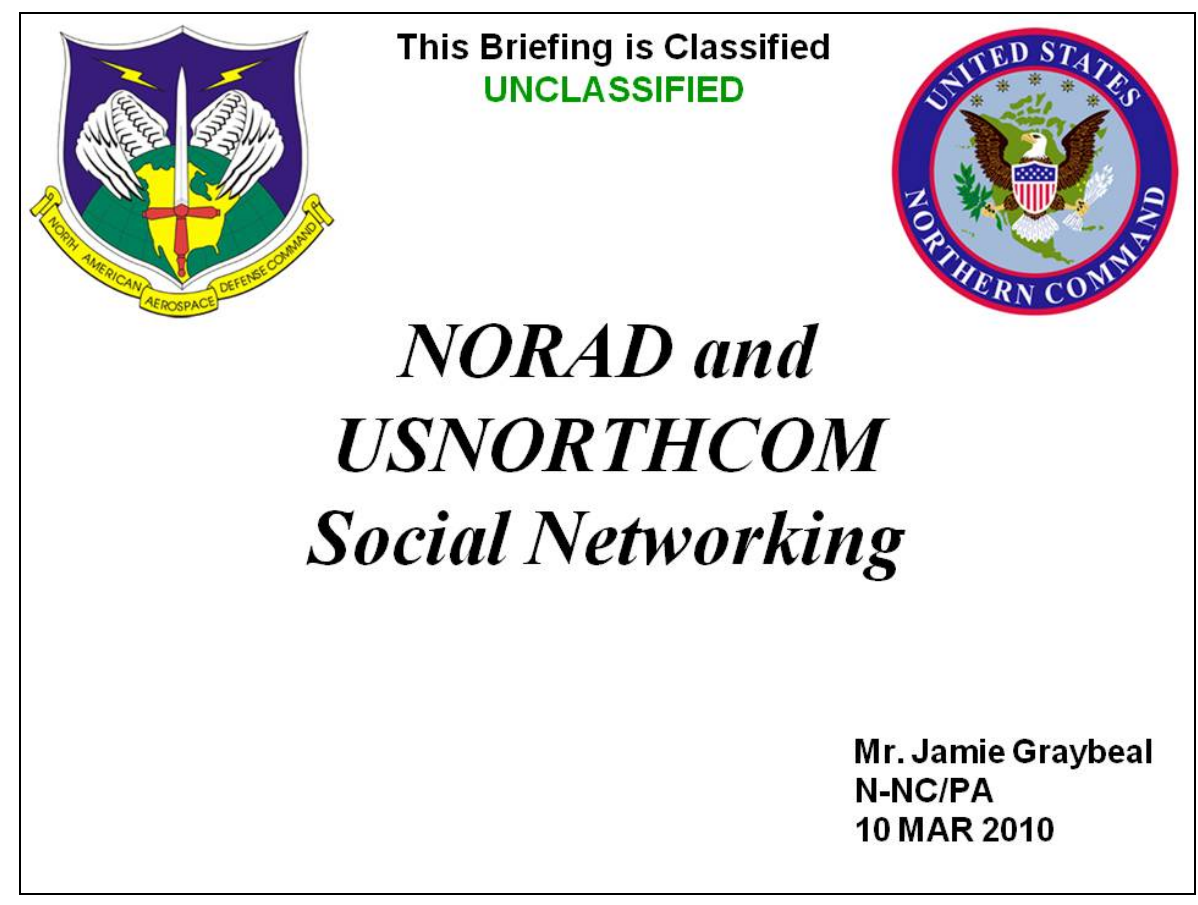

- Who We Are
- Why It Matters To You!
- Why Social Media?
- Our Social Networking
- Our Experial Media \& Our Missions
- Social Networking \&
- The Military
- Questions
UNCLASSIFIED



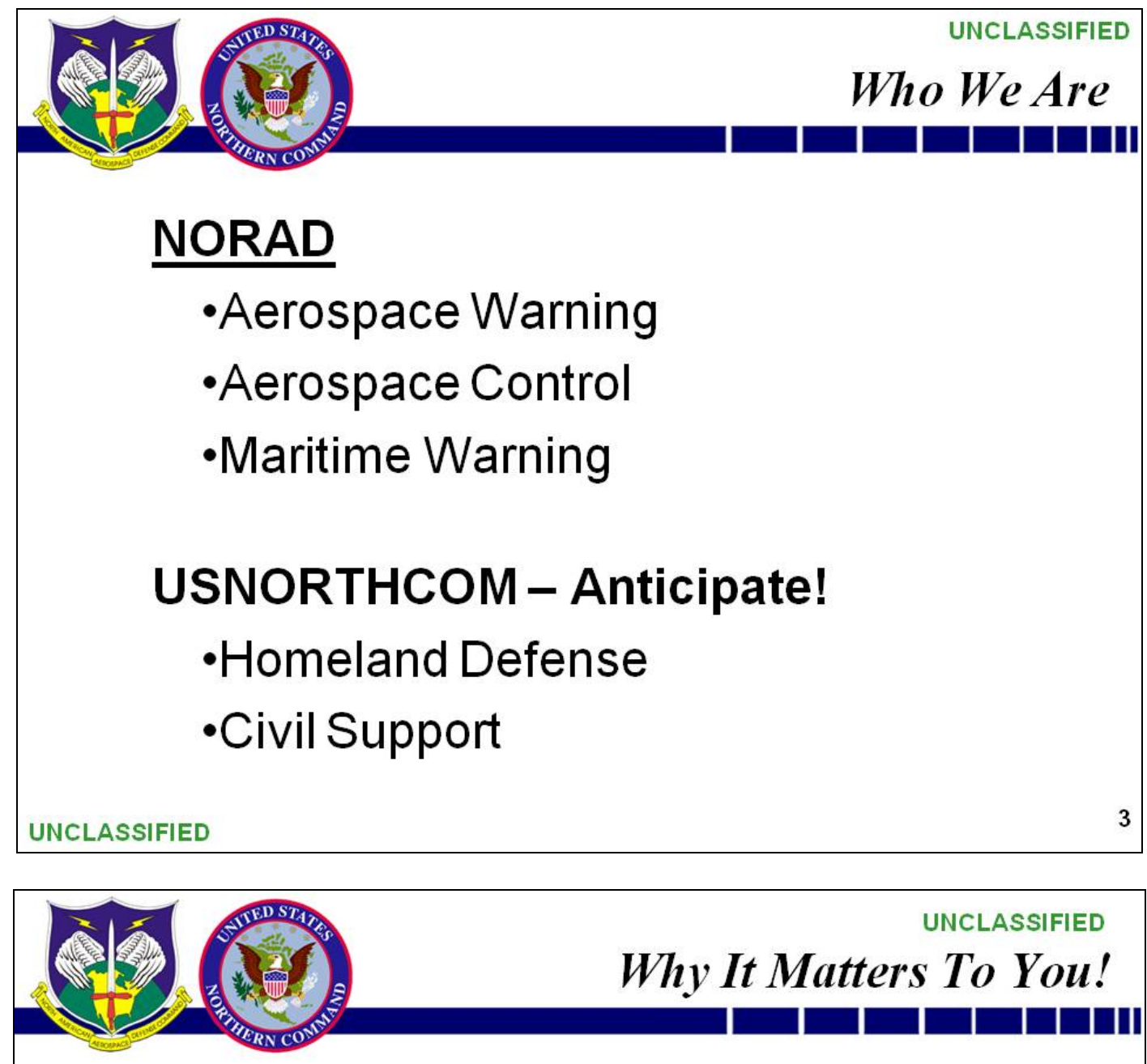

- Domestic disaster relief operations during fires, hurricanes, floods and earthquakes

- Managing the consequences of a terrorist event employing a weapon of mass destruction

- Provides assistance to a Primary Agency when tasked by DOD

- Per the Posse Comitatus Act, cannot become directly involved in law enforcement 


\section{Why Social Media?}

- $92 \%$ of Americans get news from multiple platforms

- Internet $3^{\text {rd }}$ most popular news platform - behind Local and National TV News

- Portable: $33 \%$ of cell phone owners now access news on their cell phones.

- Personalized: $\mathbf{2 8} \%$ of internet users have customized their home page to include news from sources and on topics that particularly interest them.

- Participatory: $37 \%$ of internet users have contributed to the creation of news, commented about it, or posted it on social media sites like Facebook or Twitter.

- $75 \%$ get news forwarded through email or posts on social networking sites

- $52 \%$ share links to news with others via those means

- Pew Internet Study (Mar 2010)

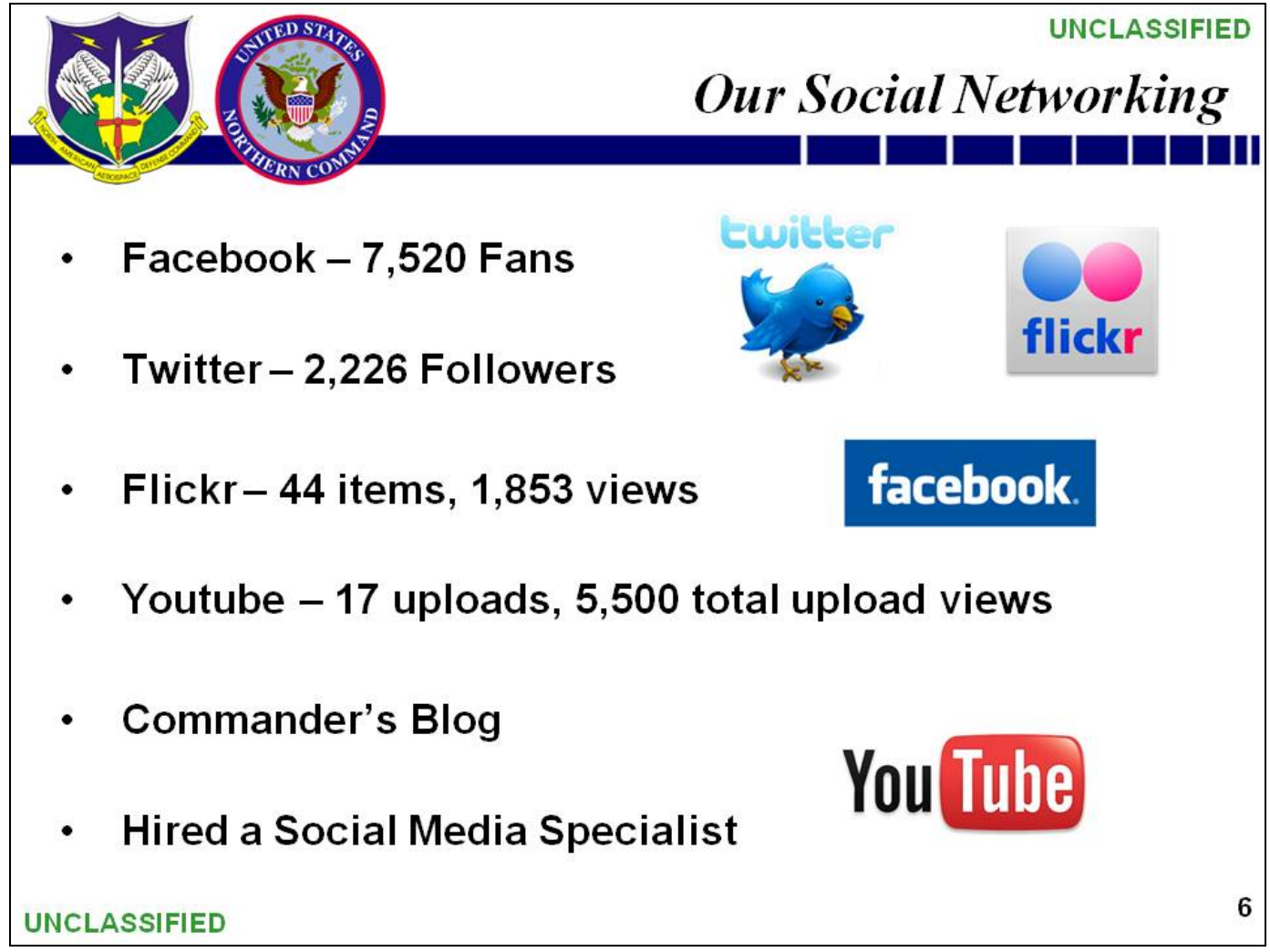



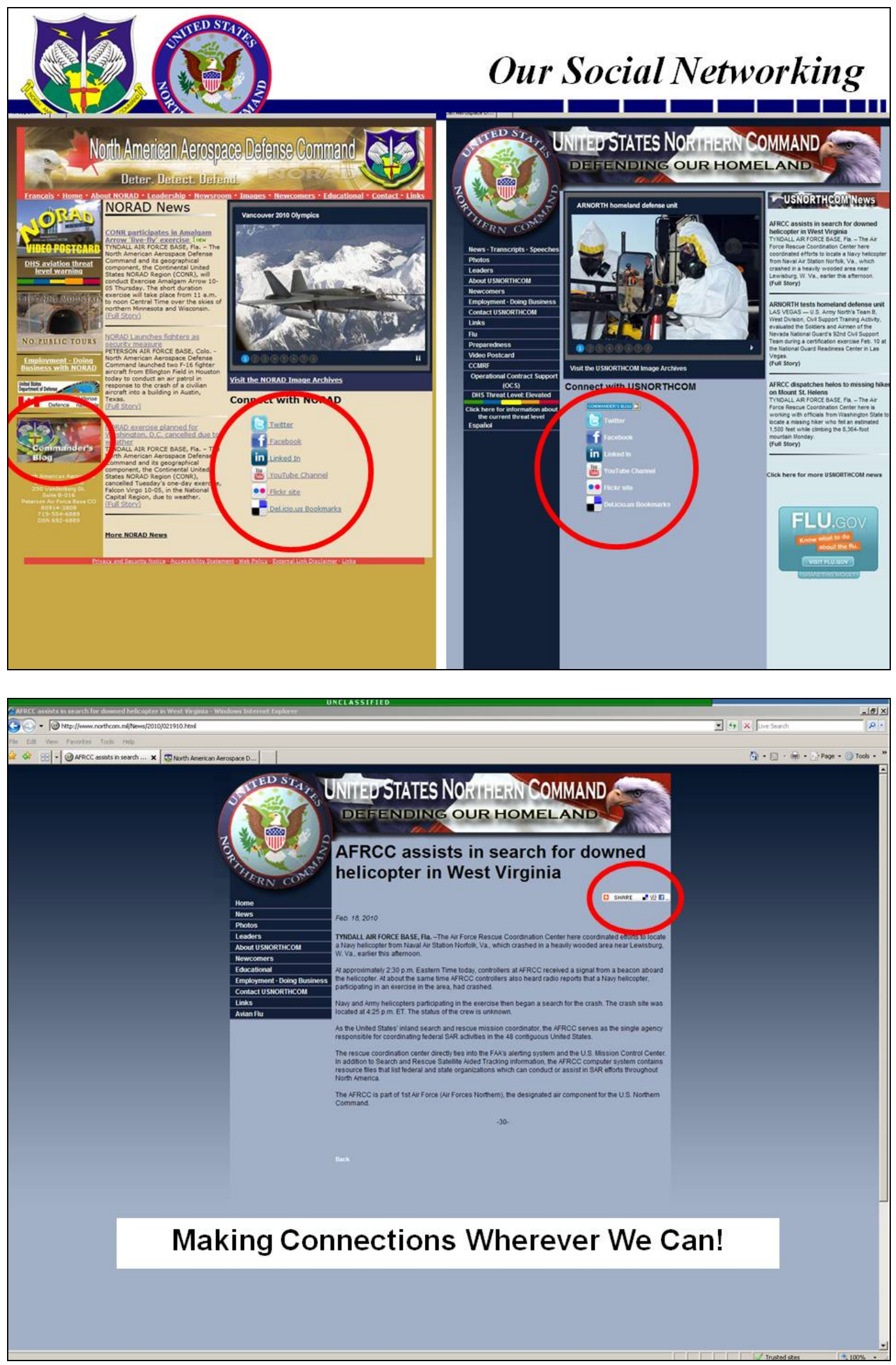


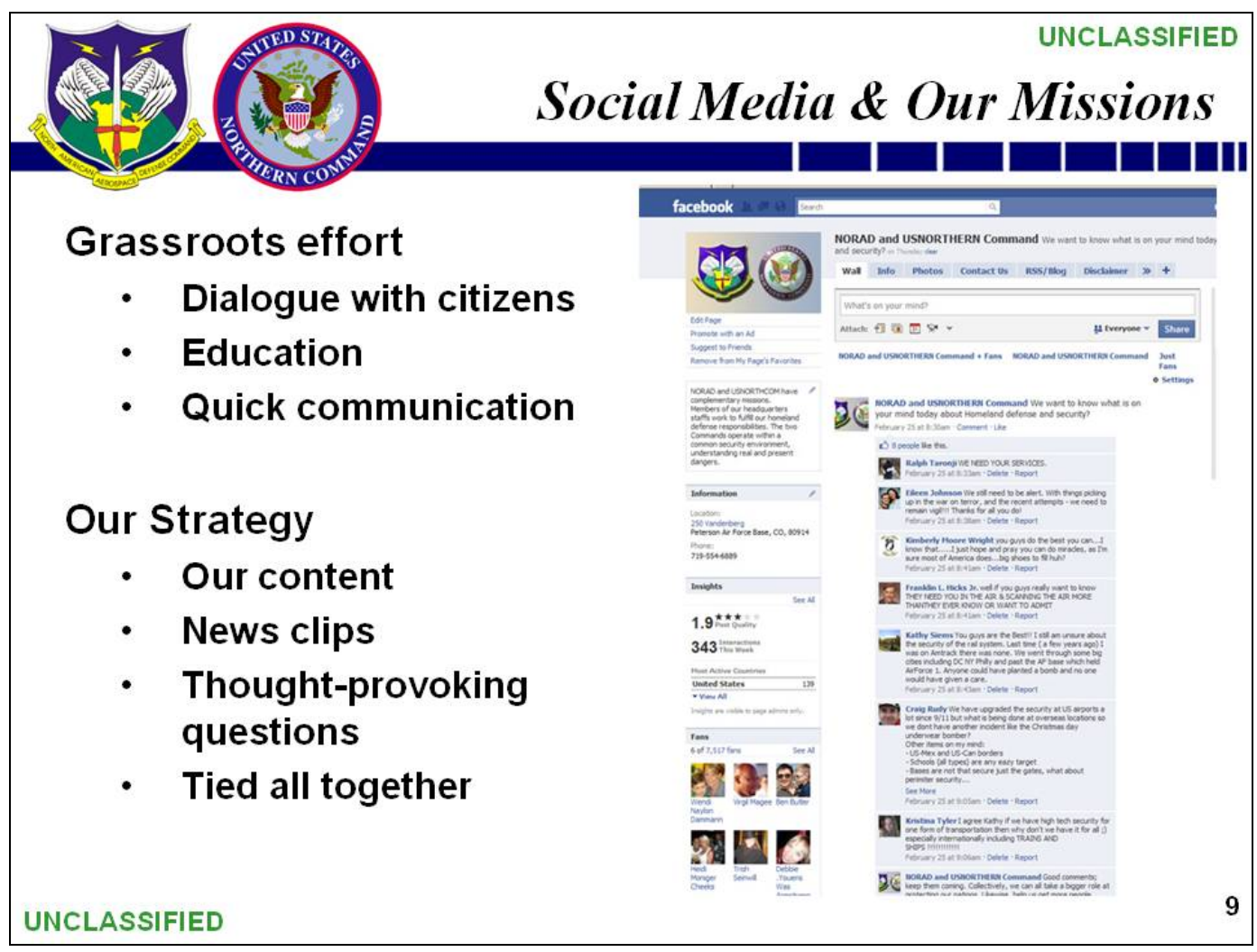

Fan Requests
- Technology
Our people
Individual missions \&
events
Comments
Haiti Earthquake
response
Hurricane Katrina
response



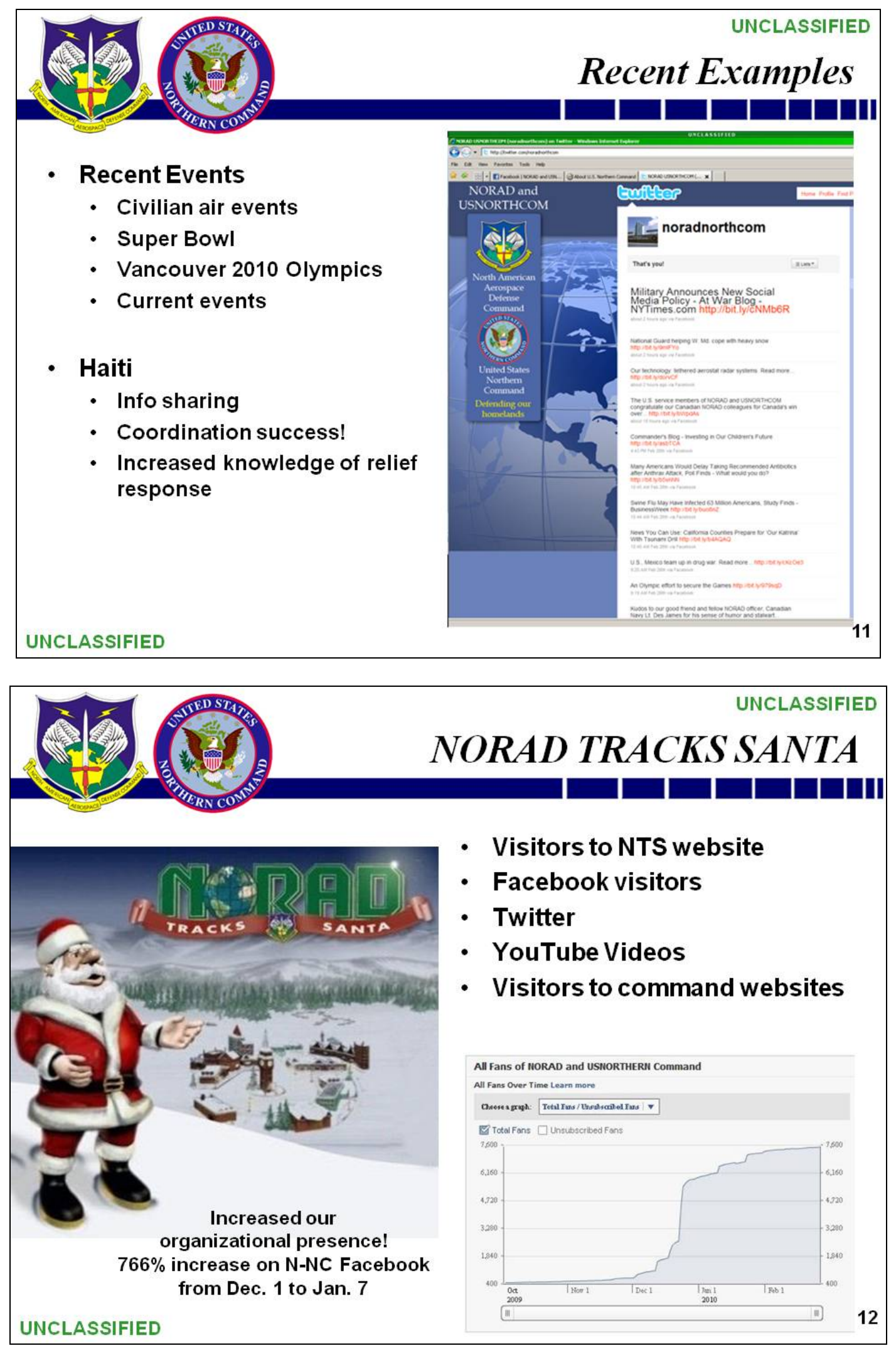


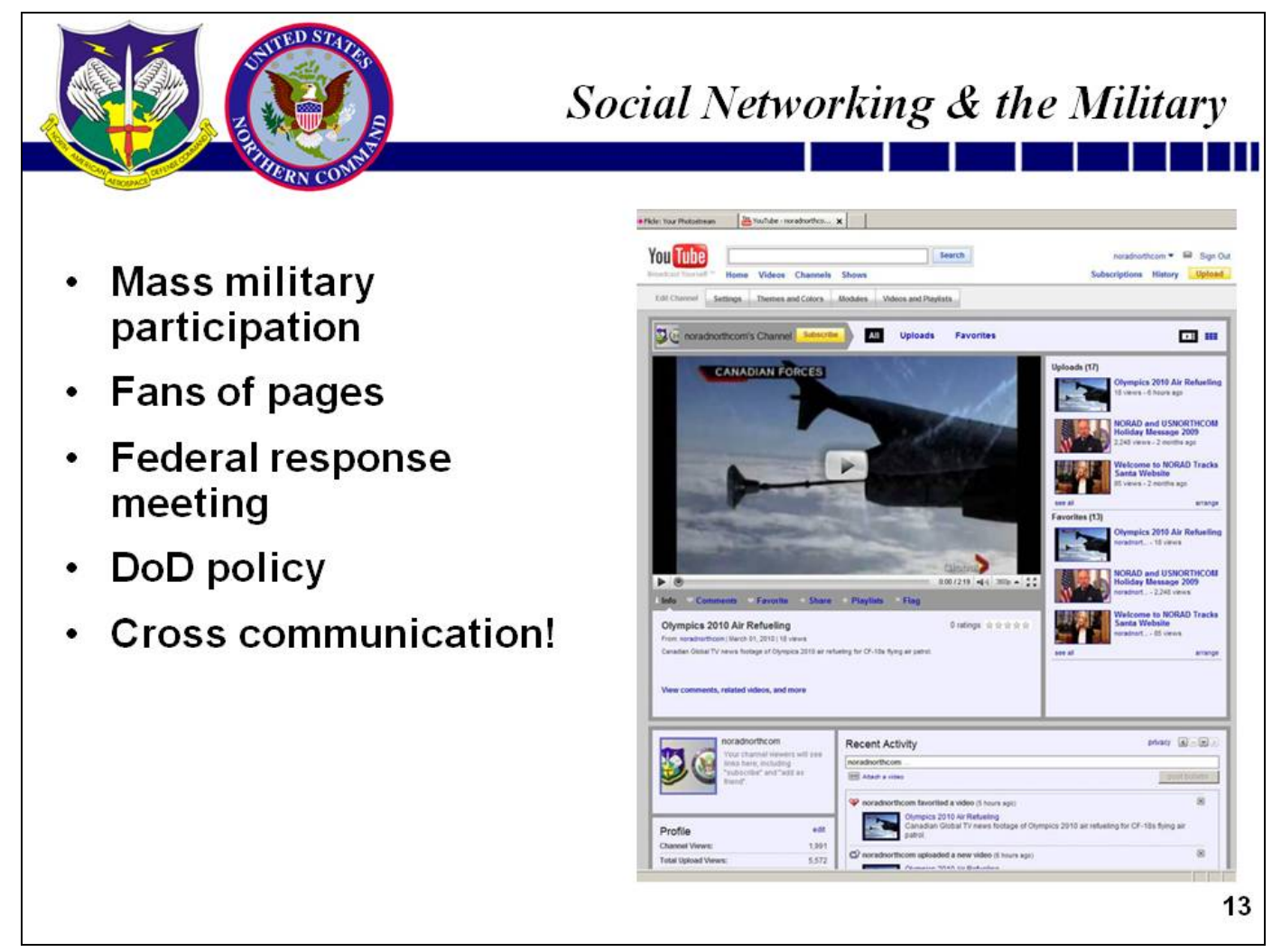

- Increase fans \& followers
- Increase awareness of missions
- Increase agency partners cross communication
- Be the site for military emergency information
- Keep up with the main-stream Social Networking
UNCLASSIFIED




\section{B-4 Laurie Van Leuven, Strategic Advisor and Manager, Seattle}

Public Utilities
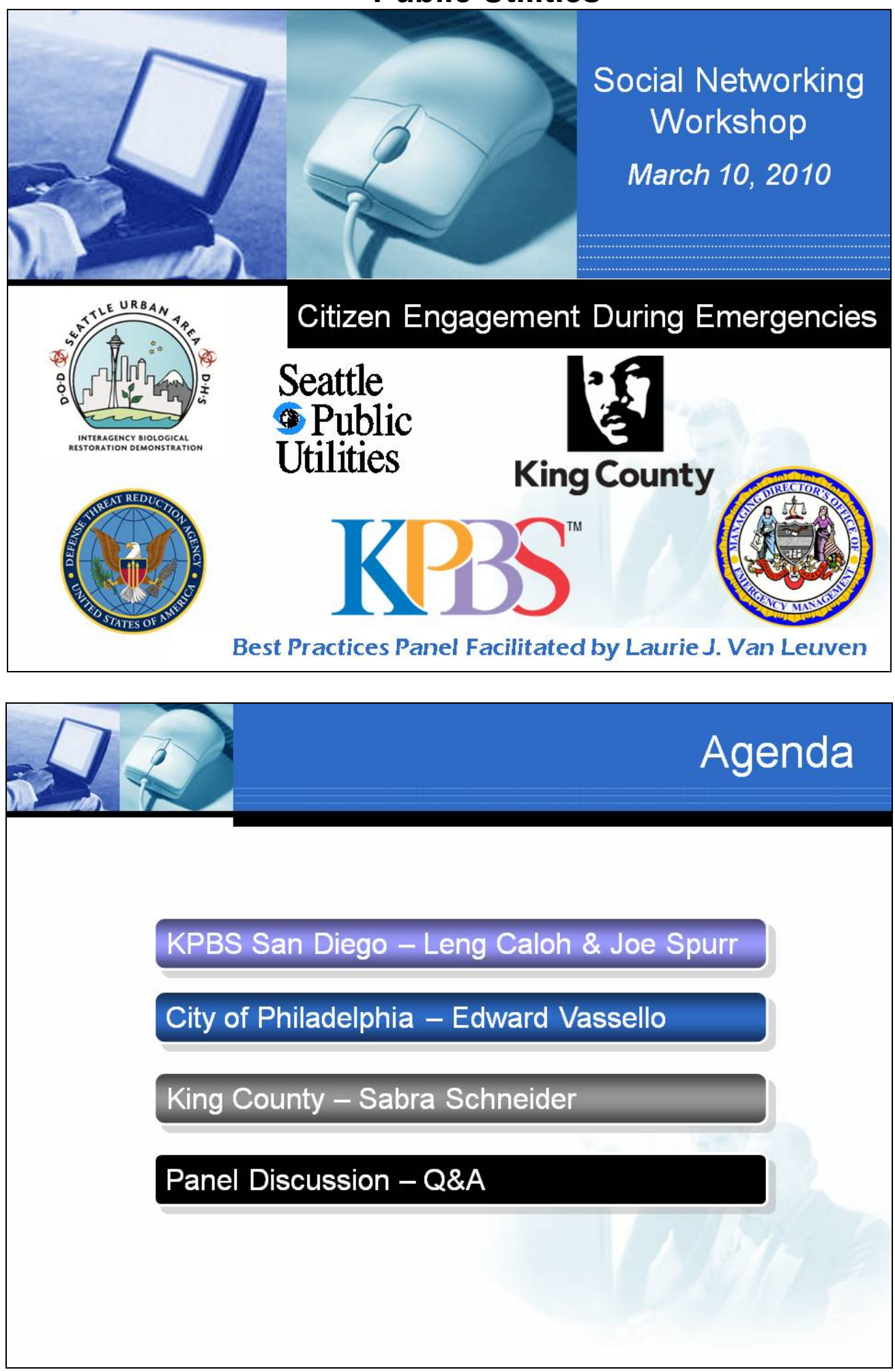

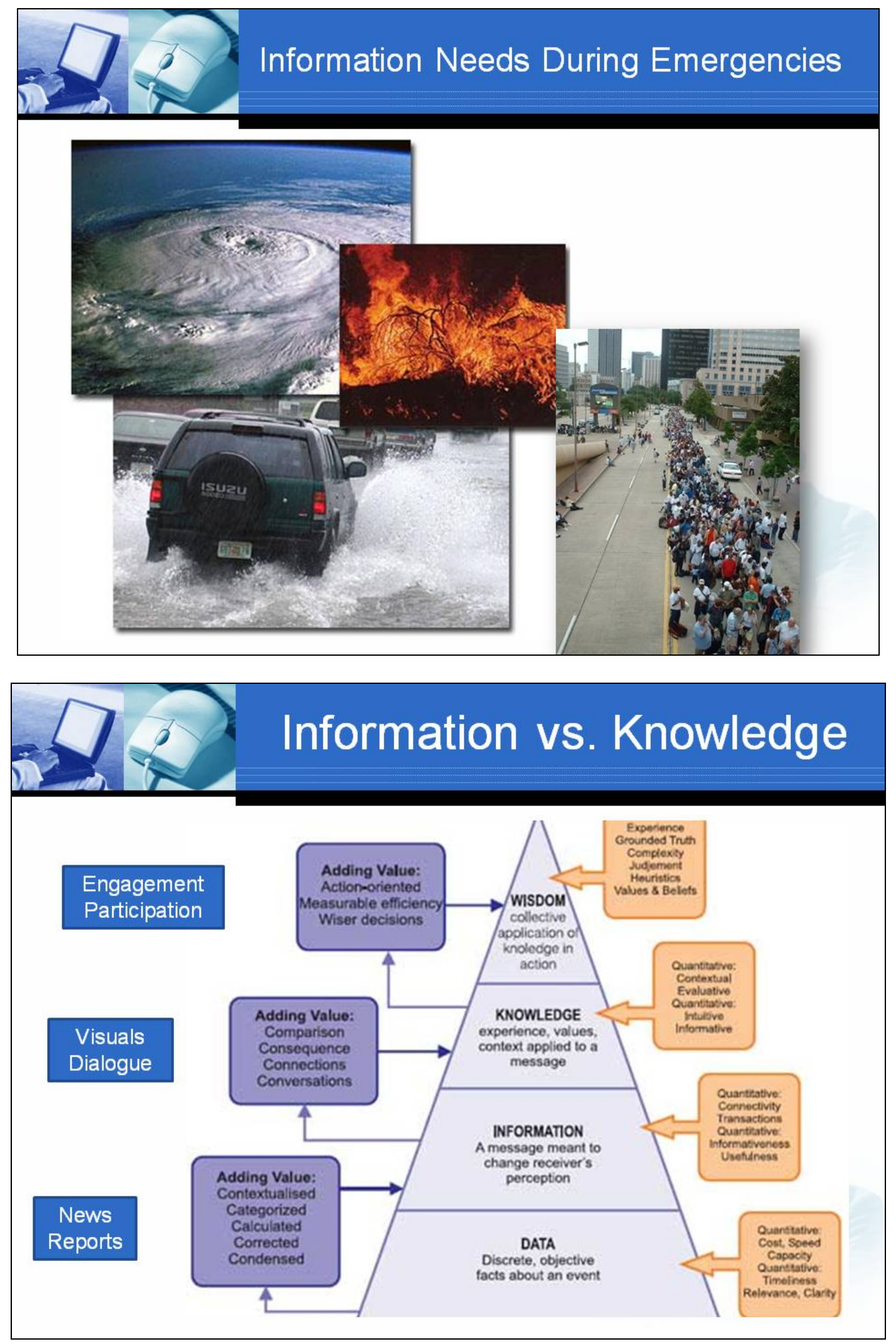

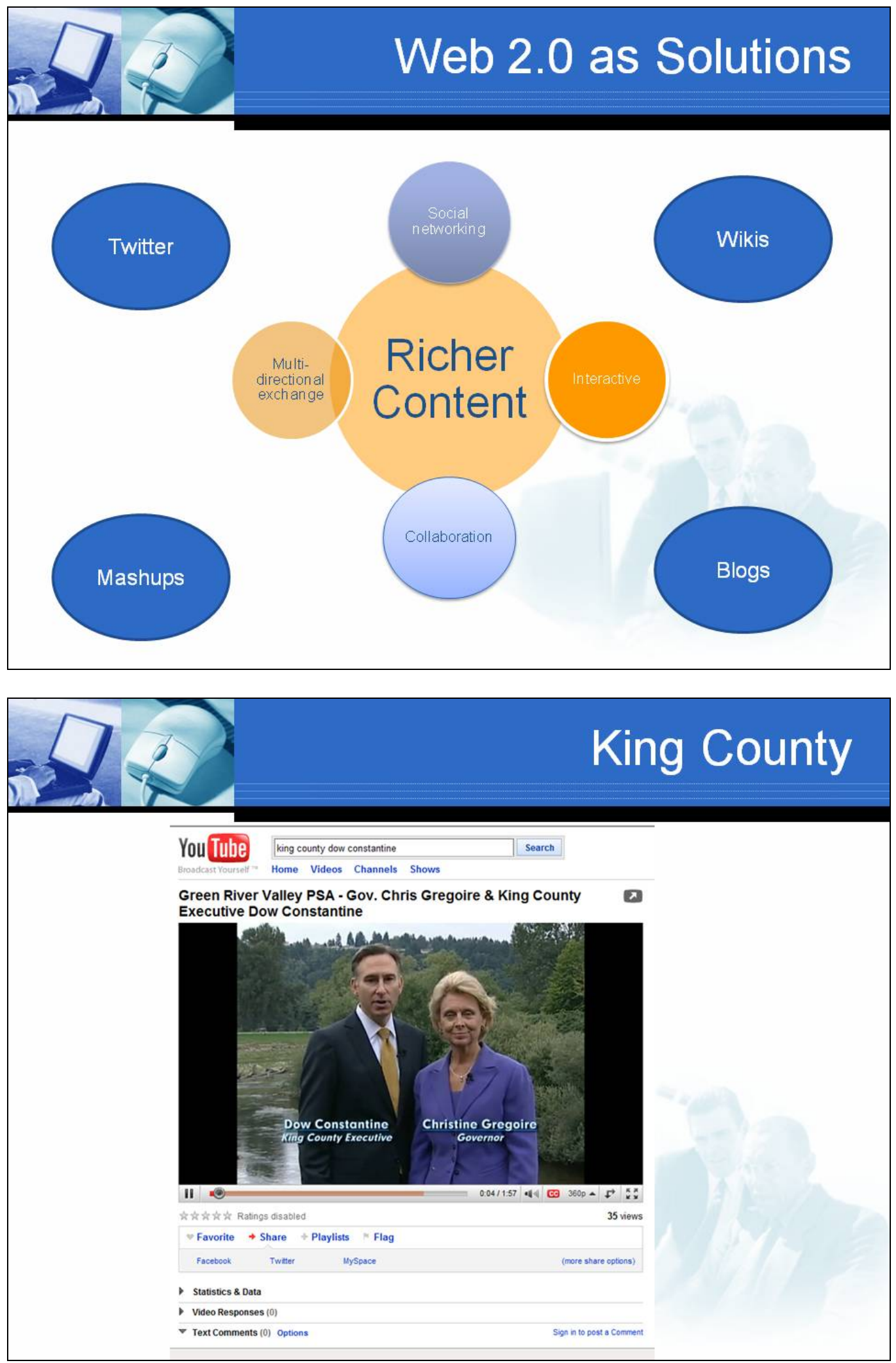

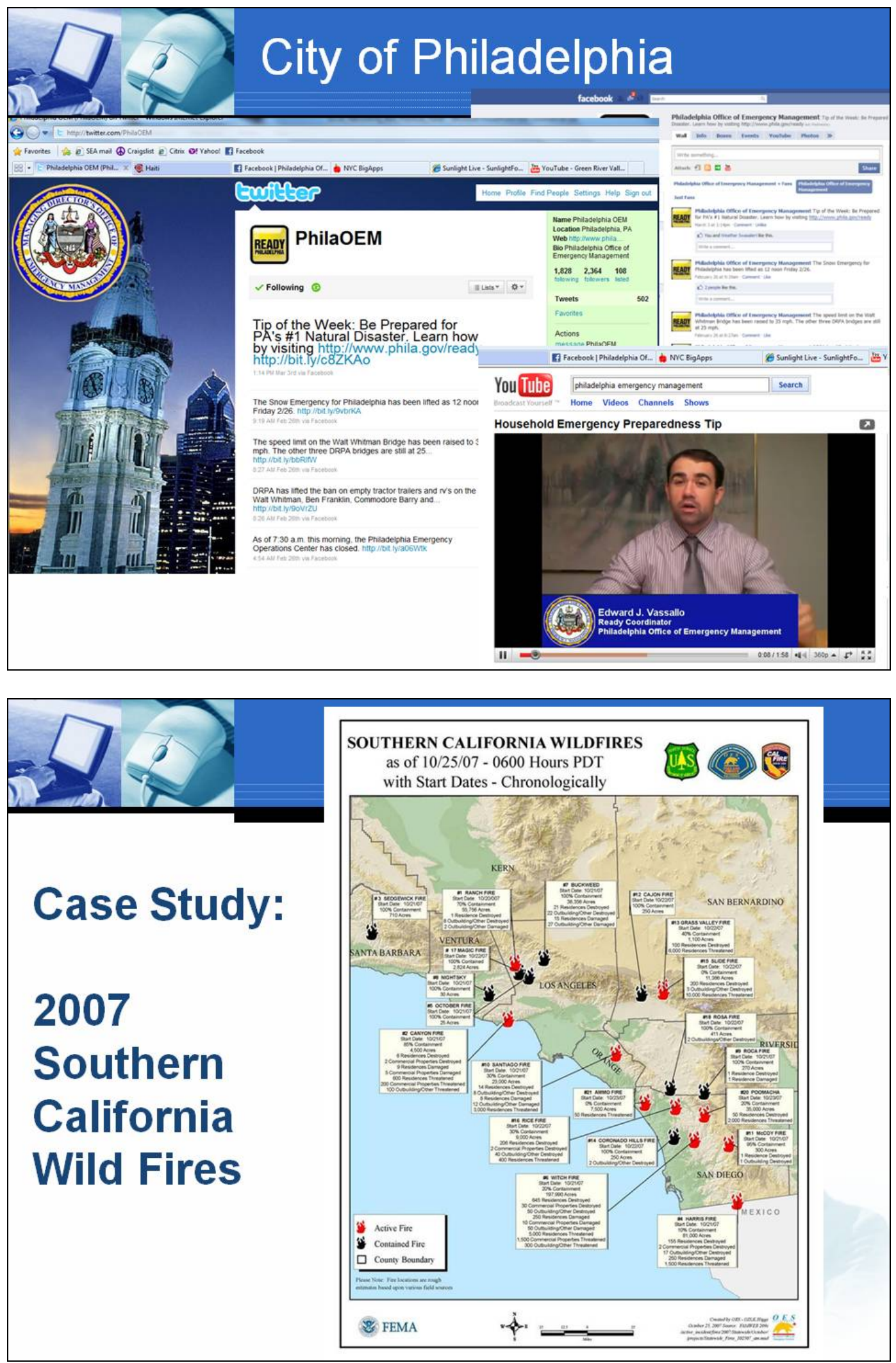


\section{California Wild Fires}

- 24 fires affecting seven counties

- 522,168 acres burned

- 10 fatalities

- 147 injuries

- 2,180 homes and 927 other buildings destroyed

- 321,500 people evacuated

- 26 hospitals evacuated

- 22,195 persons sheltered in 54 sites

- 20,000 mutual aid responders from 31 states, Mexico and Canada

10 Meeting the Info Demands

- News releases were the primary information sharing output. Other methods included talking points, ongoing media updates, and an information phone line.

- The disaster consumed all traditional media outlets in California and placed a strain on existing information systems.

- Citizen Frustrations

- Web 2.0 Technologies Filled In The Gaps 


\section{Independent Citizen Reporters}

Flickr User \#1: About 3:30 a.m. looking southeast from Old San Pasqual. This is a very short distance from our house. Escondido, CA.

Flickr User \#2: I hope your house was spared. This looks too close from all I've been seeing in the news. Be safe and my prayers are with you and yours...

Flickr User \# 3: I saw this coming to my house too. I live in Rancho Bernardo. It's really horrifying to wake up in the middle of the night and see a massive wall of orange ready to swallow you whole. Hope you are doing well and I wish you luck with recovery.

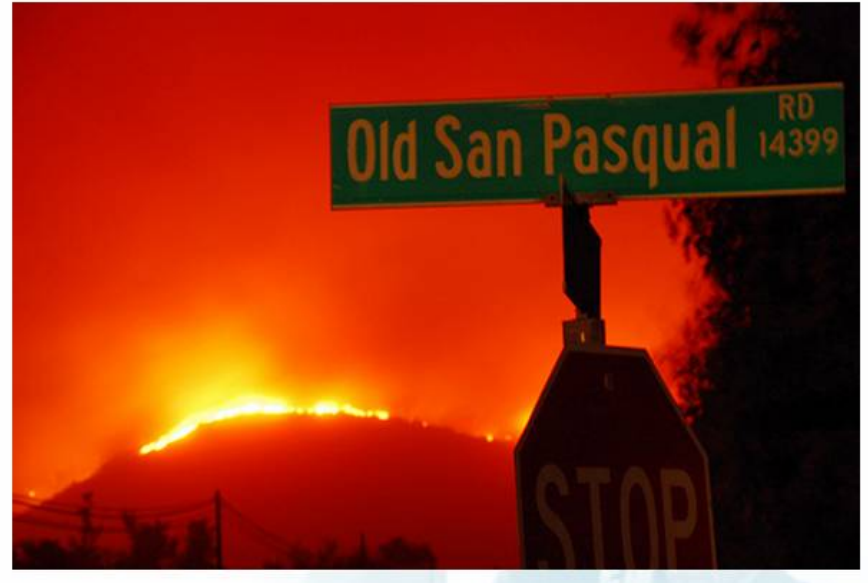

Flickr Information Exchange as a Coping Mechanism (From: Flickr.com)

\section{Progressive Media Outlet}
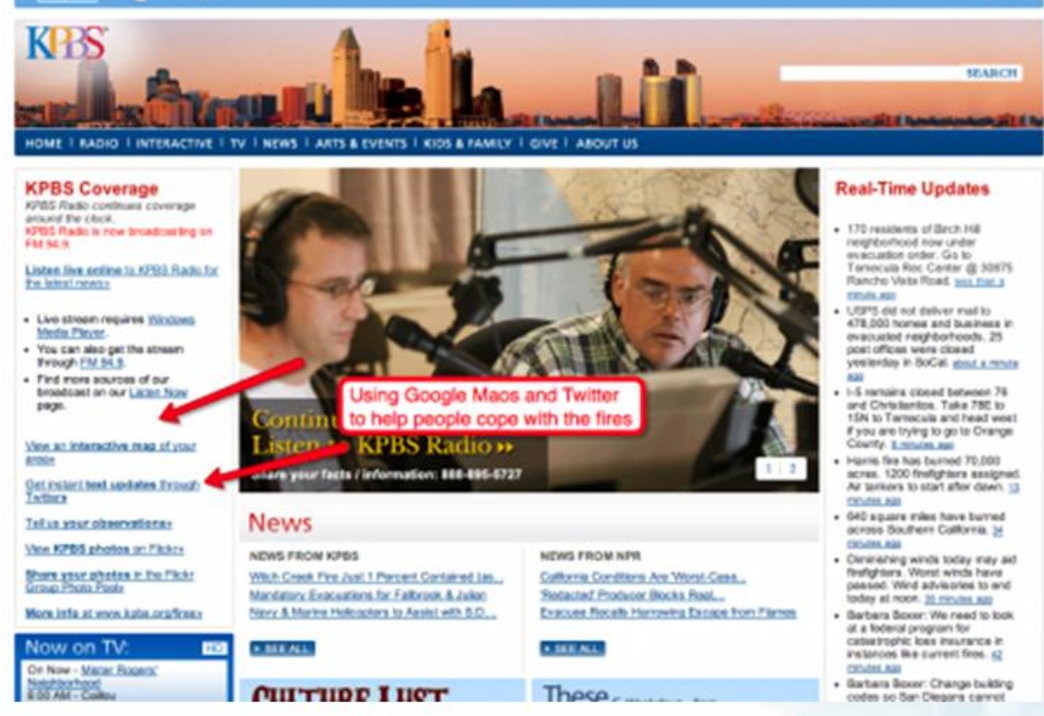

\section{KPBS}

-Linked to Google Maps -Used RSS feeds

-Linked to Twitter -Linked to Flickr - Invited contributions -Adapted as they went 
B-5 Leng Caloh, Convergence Editor and Joe Spurr, Web Developer, KPBS

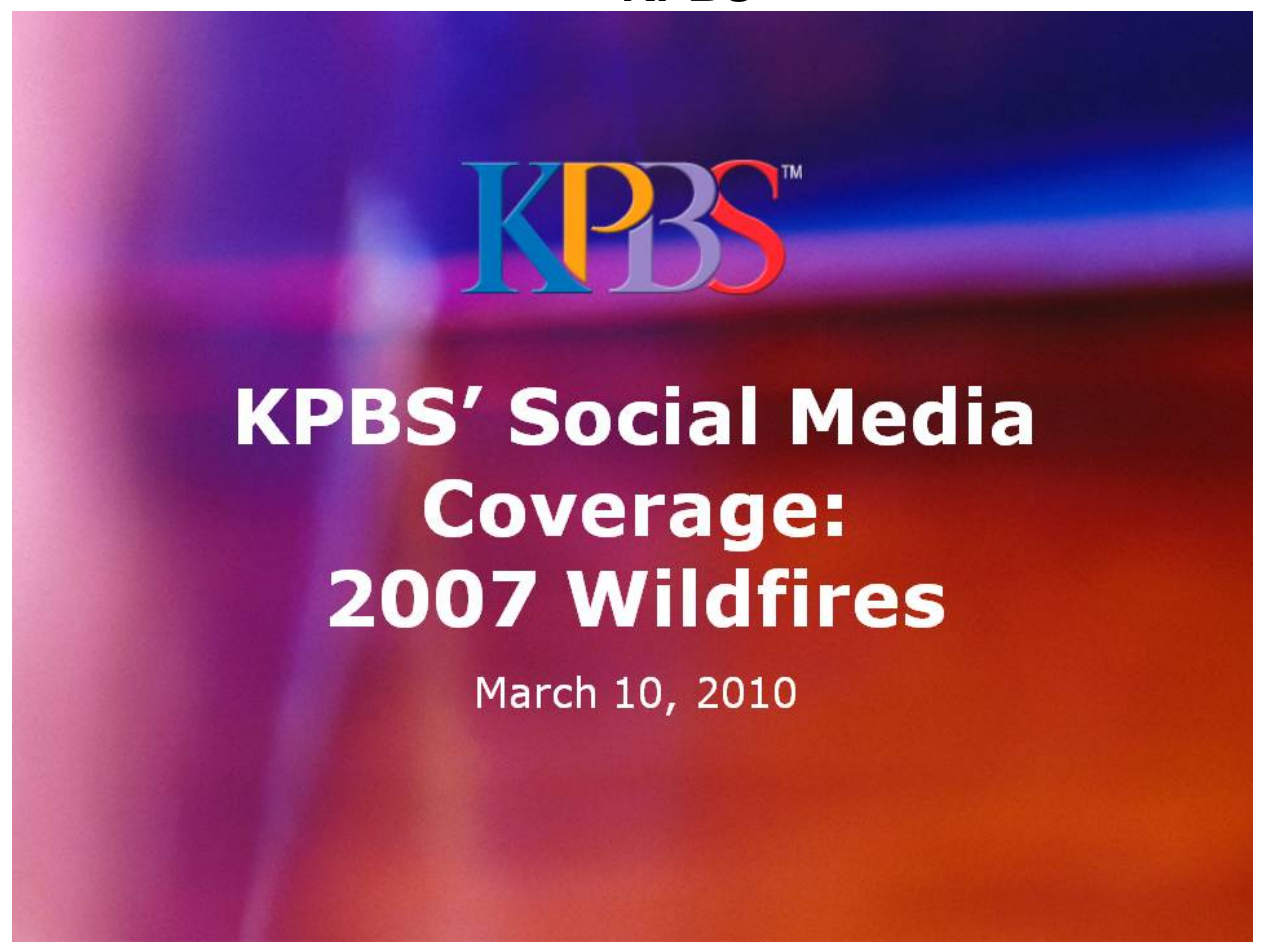

\section{Public Need for Information}

- 30x normal traffic within first few hours

- Public expectation of real-time updates

- ... but they faced lag time of several hours:

- Data gathered.

- Map created. Output to PDF. Sent to PIO.

- PIO emailed PDF to press.

- KPBS broadcasted the information, and we manually updated our online map! 


\section{Google MyMaps}

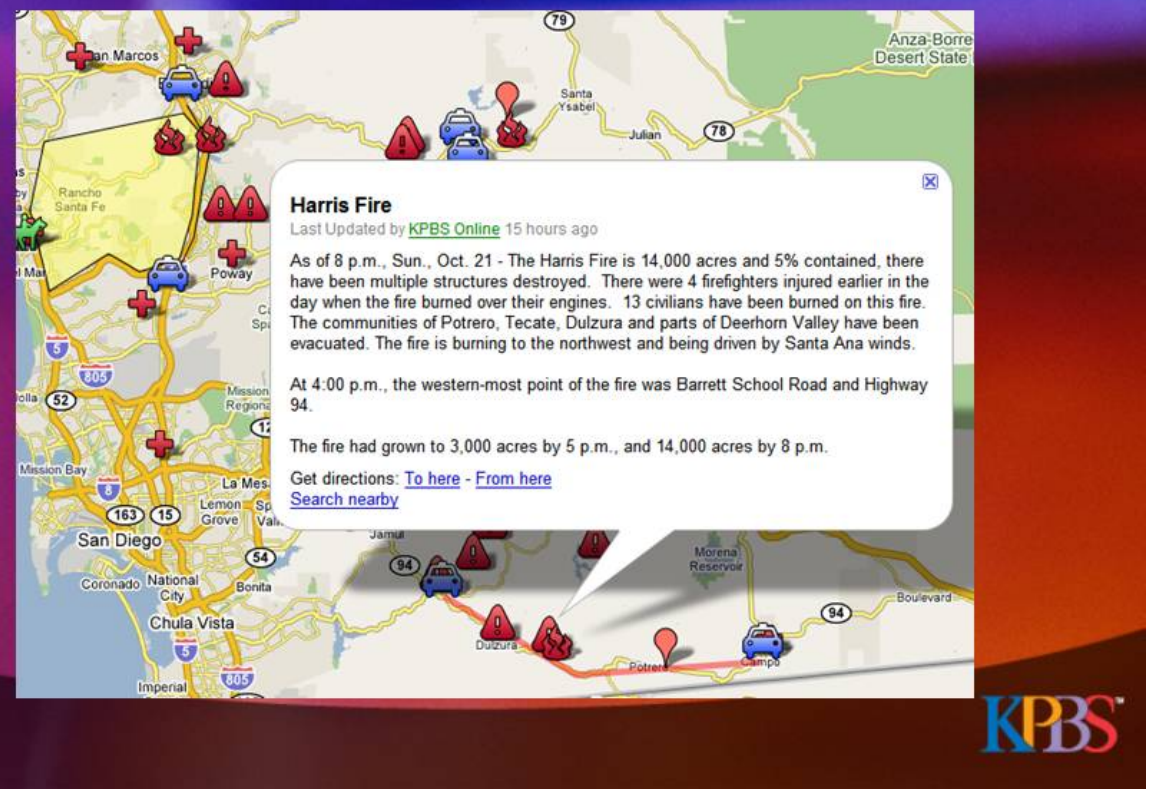

\section{Google's Investment}

- Server support

- Feature upgrades

- Google Disaster Response Team

- Vizlab heat map 


\section{Gov't Agency Use}

- Calfire embedded our map on their home page

- Email: "We at Transportation Management Center are using your [map]. It has been a great help to us. Please keep on updating this site as many agencies are using it."

- Wouldn't it be more helpful to have the data direct from public safety agencies?

\section{Imagine the Possibilities}

- Real-time data updates - direct from the frontlines

- Layered maps from different agencies - fire boundaries, road closures, evacuation centers - plus layer with public reports

- A "public scanner": Public reports via Twitter - filtered, vetted, verified... 


\section{Twitter}

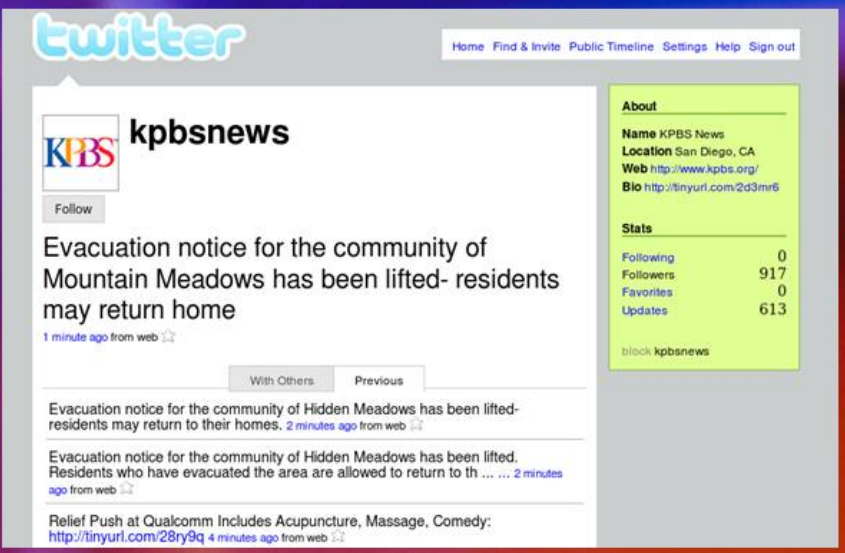

- Text alerts: "I kept my cell phone with me in bed and kept checking it all night."

\section{Twitter Audience Has Grown Significantly}

\section{Online}

Growth in Audience for Twitter.com

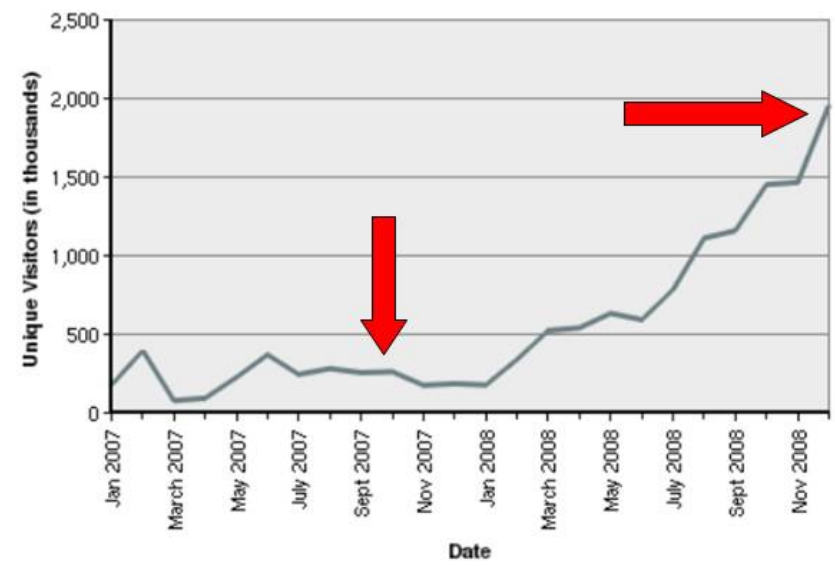




\section{"New Volunteerism"}

- Haiti / Chile

- OpenStreetMap

- Google Person Finder

- CrisisCamp

Follow @acarvin on Twitter

\section{Haiti Google Map}

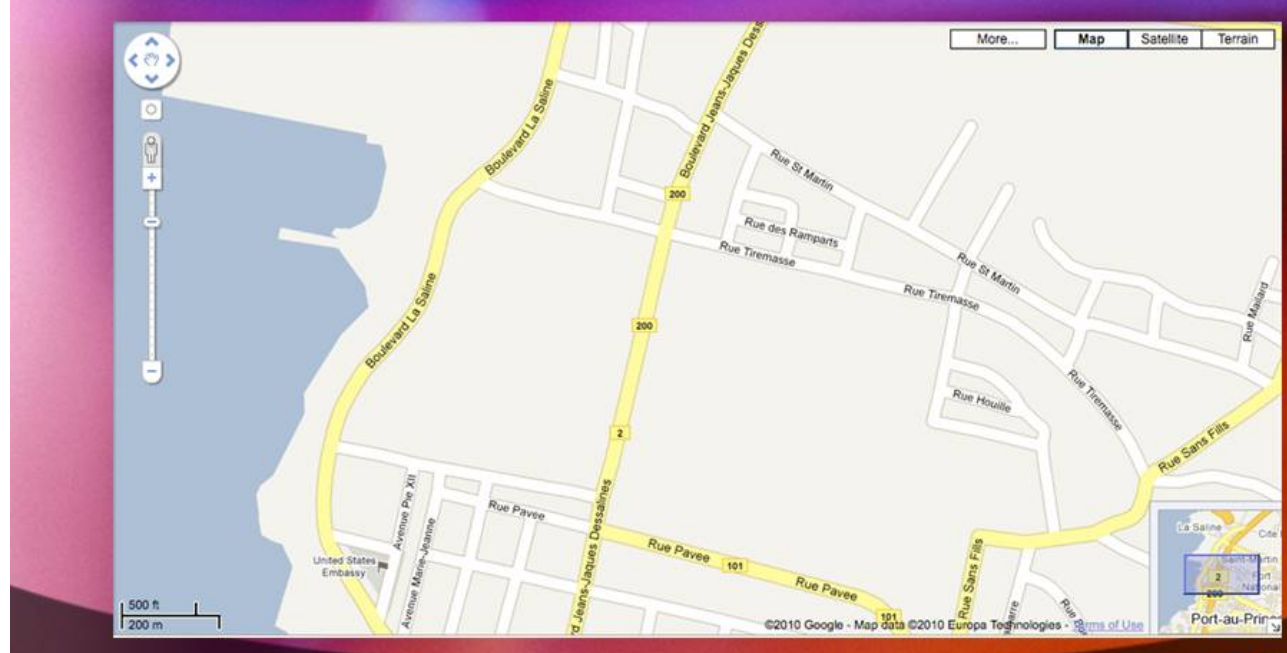




\section{Haiti OpenStreetMap}

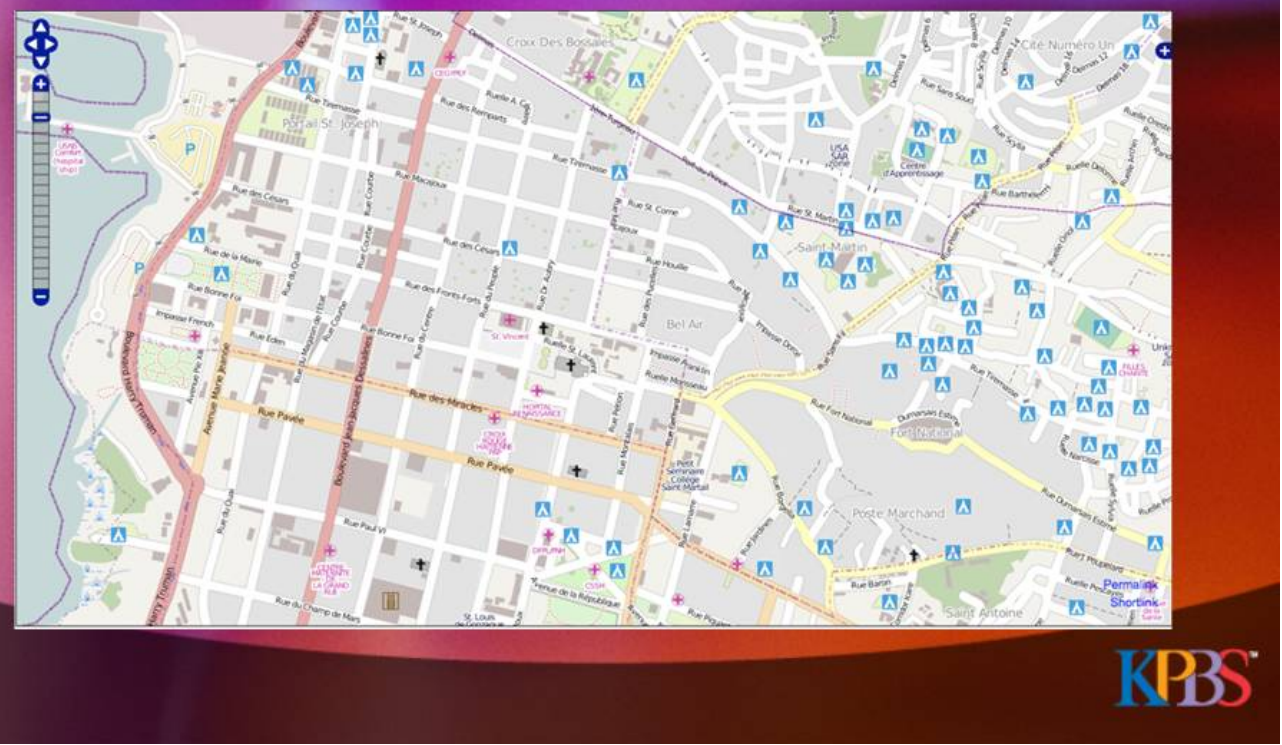

\section{Transparency and Innovation}

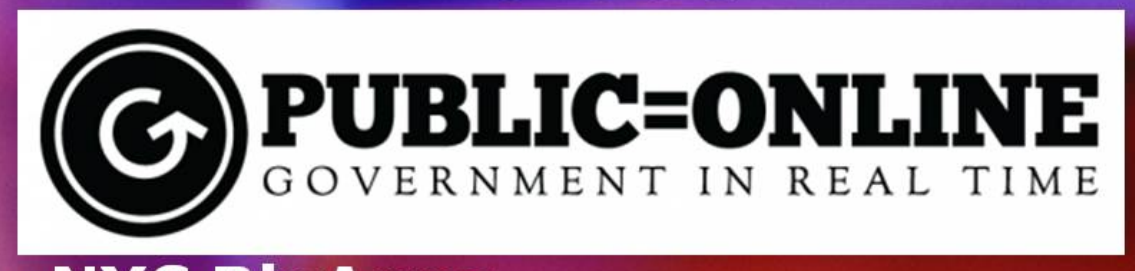

- NYC BigApps

- Cultivating community before a disaster

- nycbigapps.com/application-gallery/

- Sunlight Foundation

- http://sunlightfoundation.com/live/

- Transparency Camp
- March 27 - March 28, Washington, DC 


\section{Disaster's Opportunity}

- In times of chaos, improvisation rules

- Look for ways to eliminate organizational hurdles now, before you're hampered when it matters

- Be ready to be open

- Consider a community of PIOs, etc., as a support mechanism in times of need

\section{Our (Public Media) Wish List}

- No more PDFs by email

- Press releases via RSS for easy access and sharing

- Just blog it

- Make a spokesperson available to answer questions from the public on radio

- More open access to EOC \& data

- Automated ways of getting info out more quickly

- Relationships and communication prior to emergency

- Trust the public's ability to make sense of the information, and to contribute to the community's understanding of the crisis 


\section{The Conversation is Happening}

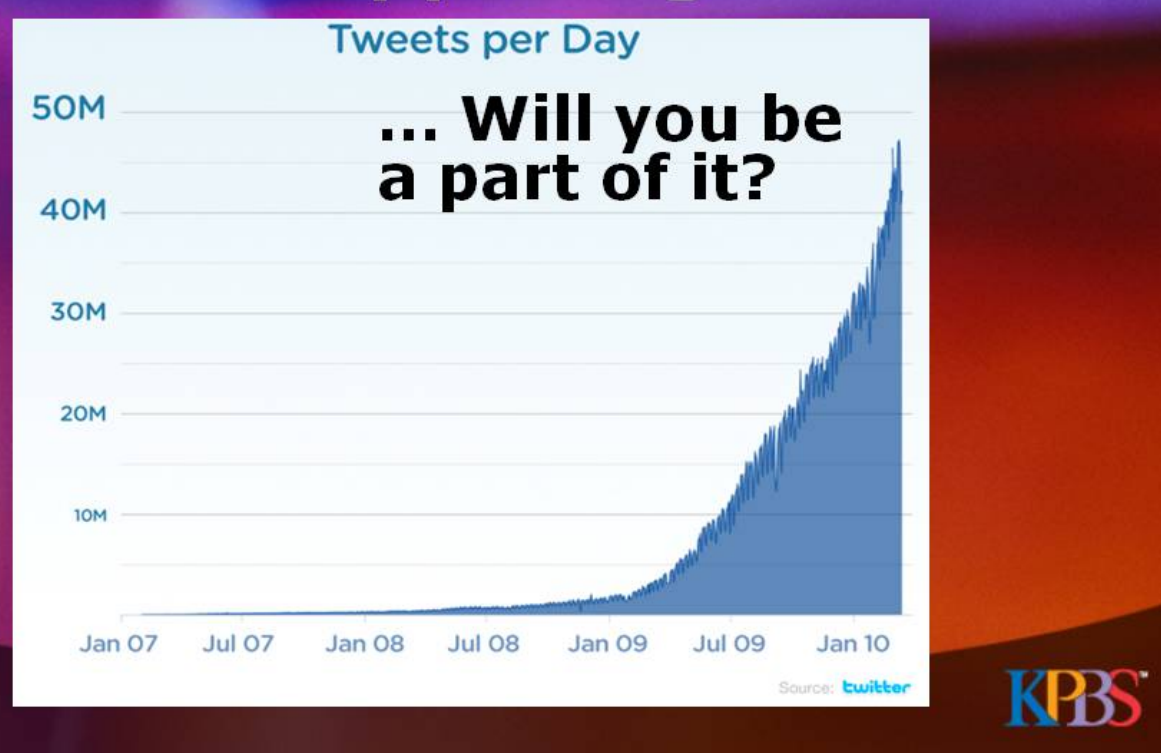




\section{B-6 Sabra Schneider, Web Master, King County}

\section{Leveraging your social network during an emergency}

Presented by Sabra Schneider, King County Sabra.Schneider@kingcounty.gov

\section{Overview}

* Establish voice, credibility and connection before the emergency

* How/when to release the message, why more is better

Staffing social media, before during and after the crisis

Tools and website integration 


\section{Houston Chronicle and Ike}

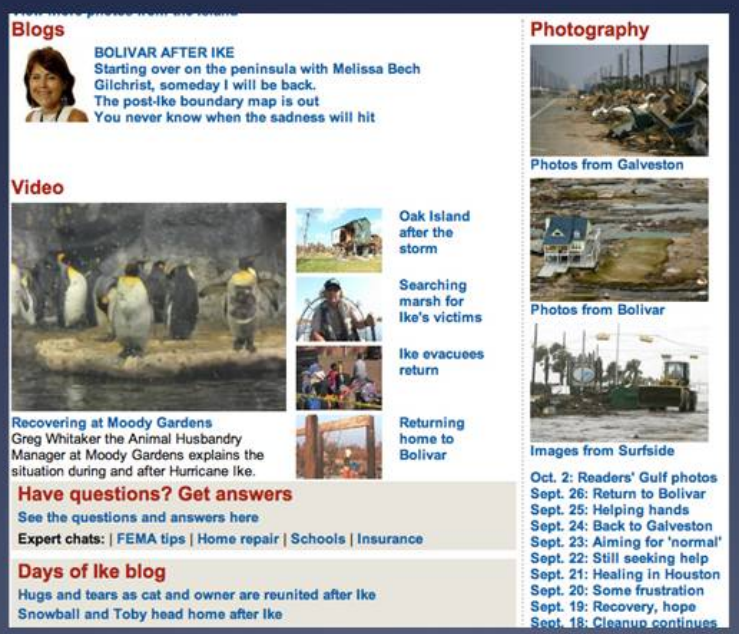

\section{Connect before the crisis}

* Establish the technical connections (what is being RSS fed?, be efficient)

* Create effective and well trained work teams

Connect with the public

Don't forget about your media partners

Leverage the wisdom of the crowd 


\section{Green River Flood}

| HOME | NEWS | SERVICES | DIRECTORY | CONTACT |

Search

\section{Regional flood preparedness}

Yourre In: Prepsere for floods

|ppintapienouy / gmemap

\section{Prepare now for floods}

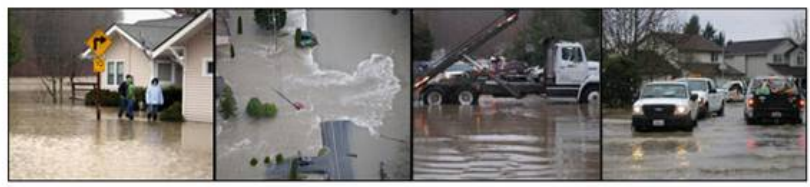

Serious flooding may occur in some areas of King County this winter

Homes, farms and businesses in the Green River Valley are

particularly at risk. Residents should prepare now for the winter

Translations

Green River

flood

preparation

Emergency

Residents, businesses and farms below the Howard River Valley should preepare now for a higher risk of flooding. Parts of Auburn, Kent, Renton and Tukwila - could be flooded and evacuations in some
communities are possible.

\section{Trusted source}

* Establish your credibility and critical mass before the crisis

* Keep the communication two-way

* Use information from the public even with caveats, for example "Residents reporting ice/snow in Issaquah, what are conditions in your neighborhood?" 


\section{Share offen and openly}

* Public expects up to the minute current information

* They will turn elsewhere if they don't get it

* 10 levels of approval won't work

* It's not always a press release

One update can and sometimes should feed all social networks

\section{Case słudy: KC Votes}

- Goals: To showcase final poll election. To create a new media message about transparency, better systems and voter involvement. JIC established

- Used Twitter, Flickr, blog, YouTube, kingcounty.gov and most importantly: VOTERS

- Why and how?

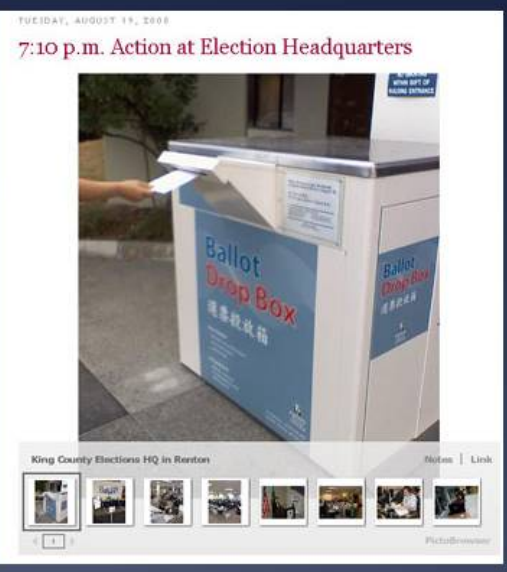

Used flickr, blog and code to create automatic galleries easy to deploy from the field. 


\section{Four (social) stages}

* Four stages of emergency planning: mitigation, preparedness, response, recovery

* Use your social networks to address all three not just the response phase

* The public will expect current, frequent and open updates

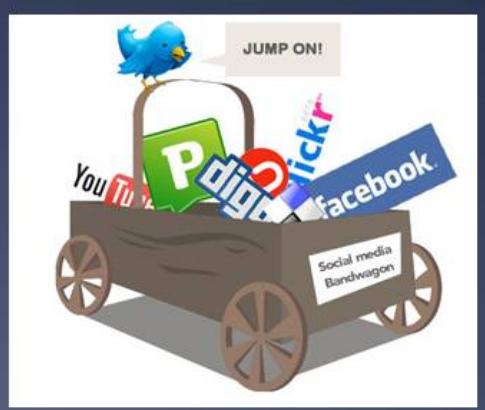

\section{Staffing needs}

* Build into JIC staff plan

* Should be cross trained for social media plus (press calls, news releases, other communications functions)

Website updates also important Who is listening?

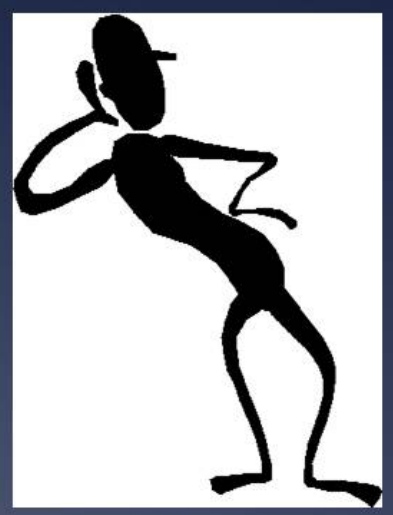




\section{Smart tools}

* bit.ly or other URL shortener

* Tweet deck

* Use the RSS feeds (site, facebook etc)

Flickr, twitter, facebook, blogs, YouTube or vimeo (top tools for an emergency, not all)

\section{Who is the credible source?}

* Government?

* Emergency organizations?

* News organizations?

* If your agency isn't the source, someone else will fill the gap.

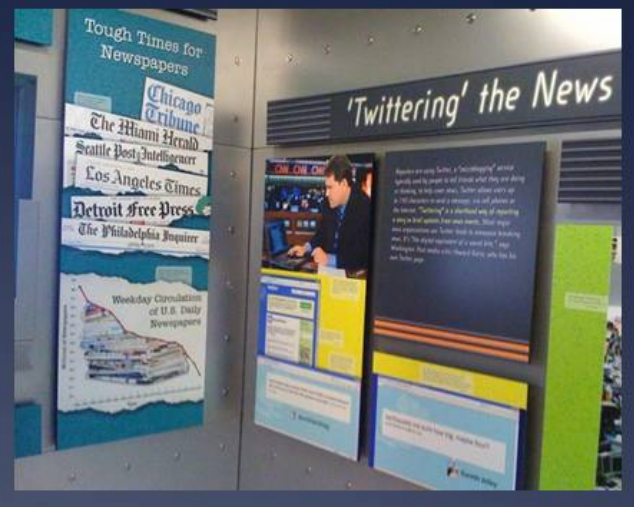




\title{
Above all, do something
}

\author{
Sabra Schneider \\ on twitter
}

twitter.com/sabrak

twitter.com/kcnews

twitter.com/kcexec

twitter.com/kcpets

twitter.com/kcmetrobus

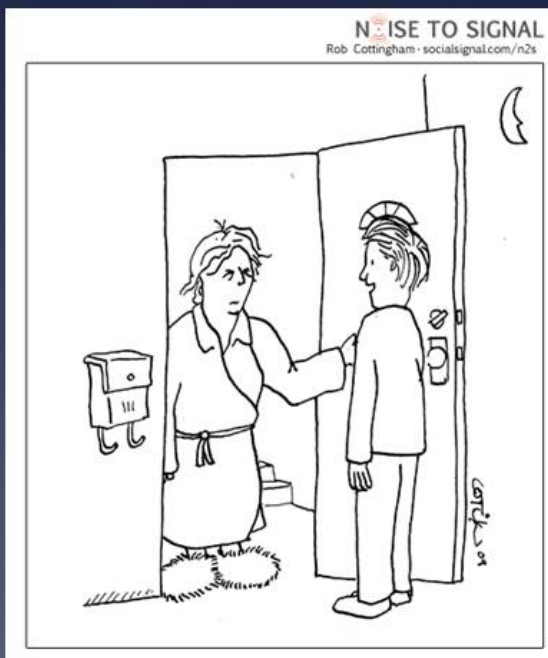

Hi! We've never met, but I noticed you stopped following me on Twitter a few hours ago. Mind if $I$ ask why? 


\section{Appendix C Biographies}

The following biographies follow the order of the program.

$$
\begin{gathered}
\text { Ann Lesperance } \\
\text { Deputy Director, Regional Programs } \\
\text { Northwest Regional Technology Center for Homeland Security } \\
\text { Pacific Northwest National Laboratory }
\end{gathered}
$$

Ann Lesperance is a senior research scientist with the Pacific Northwest National Laboratory. She has over 20 years of experience in domestic and international environmental and public health analysis, project management and program development. In addition to her environmental and public health expertise, Ms. Lesperance has a long history of being called upon to form and lead networks of collaborators on educational, analytical and policy development activities in those areas. The establishment and maintenance of extensive networks spanning the scientific, educational, and policy communities and the formation of effective interdisciplinary teams has evolve into an area of special practice and professional recognition during Ms. Lesperance's broad career.

She was also on an Inter-Personnel Agreement (IPA) assignment from the Pacific Northwest National Laboratory to EPA Region 10 serving as Manager of International Programs. In that capacity, she comanaged the region's international program and is responsible for identifying the strategic direction, partnerships and key activities for the program. Ms. Lesperance is an Adjunct Professor at the University of Washington and teaches the course on 'Puget Sound/Georgia Basin Managing and Protecting an International Ecosystem” which looks at current issues, challenges and conflicts in managing an international border from both a public policy and technical perspective. She also served on the Technical Advisory Committee of the "2007 Georgia Basin-Puget Sound Research Conference.”

As part of the PNNL's homeland security programs, Ms. Lesperance is engaging regional emergency planning professionals in identifying specific needs and technology applications in the Pacific Northwest. She is engaging with the leadership of key regional players which include those from the Governor's Office, Navy Northwest, US Coast Guard, Seattle Fire Dept., Seattle Police, EPA, Washington State Dept. of Health, University of Washington, FEMA, and others.

B.A., University of Wisconsin, Environmental Science and Latin American Studies M.S., UCLA, Public Health, School of Public Health, Environmental Science and Engineering Program 


\section{Glen L. Woodbury \\ Executive Director \\ Center for Homeland Defense and Security \\ Naval Postgraduate School}

Glen Woodbury is the Director of the Naval Postgraduate School's Center for Homeland Defense and Security responsible for leading the Center's strategic commitment to servicing the homeland security priorities of the U.S. Departments of Homeland Security and Defense, as well as local, state, tribal and federal agencies. His previous responsibilities as an Associate Director from 2004-2007 included the development of executive education workshops, seminars and training for senior state and local officials as well as military leaders. He also serves on the Department of Homeland Security's Quadrennial Review Advisory Council.

He served as the Director of the Emergency Management Division for the State of Washington from 1998 through 2004. In this capacity, he directed the state's response to numerous emergencies, disasters and heightened security threat levels since his appointment by the Adjutant General and the Governor. Mr. Woodbury was the Director during the World Trade Organization disturbance in Seattle in 1999, the Nisqually Earthquake in February 2001, the TOPOFF II Exercise in 2003, the national response to the attacks of September $11^{\text {th }}$, and many other natural and manmade emergencies and disasters. During his tenure, the division received numerous awards and recognition for national and international excellence in the areas of public education, tsunami and earthquake preparedness, hazard mitigation and homeland security.

Mr. Woodbury is a Past President (2002-2003) of the National Emergency Management Association (NEMA,), which represents all state and territorial emergency management directors in the development and advocacy of national policy, strategic and operational issues. He served as the emergency management representative to the Advanced National Seismic System Advisory Board, the Co-Chair of the Mitigation Committee, the interim Intergovernmental Relations Sub-Committee Chair to the developing National Homeland Security Consortium, and as Chairman of the Board of Directors for the Center for State Homeland Security, (a non-profit partnership of NEMA, the Adjutants General Association of the US, and Mitretek Systems.) He also served in a variety of capacities on many Washington State and national councils, committees, and professional organizations.

Glen Woodbury served in the US Army as a communications officer from 1985 until he began his emergency management career in the State of Washington as an operations officer in 1992. Prior to his selection as the agency's director, he managed the state's Emergency Operations Center for two years. He has served as an officer in the US Army Reserves and as a volunteer firefighter in East Olympia, WA.

Mr. Woodbury holds a Bachelor of Arts Degree in Engineering Sciences from Lafayette College in Easton, PA (1985) and a Masters of Arts Degree in Security Studies (Homeland Defense and Security) from the Naval Postgraduate School in Monterey, CA (2004.) He is a winner of the George C. Marshall Award, a Distinguished Military Graduate from Lafayette College and a winner of the Governor's Distinguished Manager Award in 2003. 


\section{Bill Schrier \\ Chief Technology Officer, Department of Information Technology City of Seattle}

Bill Schrier is the Chief Technology Officer (CTO) for the City of Seattle and director of the City's Department of Information Technology (DoIT), reporting directly to Mayor Michael McGinn. Seattle has a population of about 600,000 residents and a City government of about 11,000 employees. DoIT has 205 full-time employees and a budget of \$56 million. Approximately 450 employees work in information technology units throughout City government.

As CTO, Schrier is responsible to set standards and policies governing the use of information technology in City government. As Director of DoIT, Schrier responsibilities include the city's data center, computing services, information security, web site, municipal television station, community technology, electronic mail system, $800 \mathrm{MHz}$ trunked public safety radio system, telephone network, and data communications network.

The City of Seattle's website www.seattle.gov, television station and technology projects have won a number of local and national awards, including "Best of the Web City Portal” in 2001 and 2006 and NATOA's “Excellence in Government Programming” in 2007 and 2008 for the Seattle Channel. Schrier was named one of Government Technologies 25 Doers, Dreamers and Drivers in 2008 (www.govtech.com/gt/articles/268508), and a Computerworld Premier 100 Leader for 2010 (www.computerworld.com/spring/p100/detail/279). He writes a blog about the intersection of information technology and government, how they sometimes collide but often influence and change each other. It can be found at www.digitalcommunitiesblogs.com/CCIO/. He tweets at www.twitter.com/billschrier .

Schrier is a retired officer with the U.S. Army Corps of Engineers. He holds a Masters in Public Administration from the University of Washington.

\section{Sean Whitcomb Sergeant Media Response Unit Seattle Police Department}

Sean Whitcomb graduated from the University of Washington in 1994, earning a B.A. in Speech Communication. He has been with Seattle Police Department since 1995. Sean's previous assignments have included working as a patrol officer in Seattle's North Precinct, working proactive bicycle patrol in the University District and acting as the Seattle Police Drug Court Liaison for King County’s Juvenile and Adult Drug Court programs. Sean is currently assigned as the sergeant of the Media Response Unit.

In addition to his regular duties, Sean is an instructor with the Seattle Police Department Community Police Academy. 


\section{Brian Kemper \\ Signal Operations and ITS Manager \\ Department of Transportation \\ City of Seattle}

Brian Kemper is the ITS Systems Manager for the Seattle Department of Transportation. Brian's responsibilities include traffic signal operations, traffic signal maintenance, the Traffic Management Center, and he directs ITS projects and programs for the Seattle Department of Transportation. He has 25 years of experience in traffic engineering and has been the ITS Systems Manager for 10 years.

Brian is a graduate from the University of Washington with a Masters in Civil Engineering. He is a registered Professional Engineer in the State of Washington.

\section{Sheri Badger \\ Public Information Officer \\ Pierce County Emergency Management}

Sheri Badger is the Public Information Officer for Pierce County Department of Emergency Management. She also supervises the Planning, Mitigation and Recovery unit. Sheri coordinates an informal 'Emergency Communicators' group to network and bring training to PIOs in the greater Pierce County area.

\section{Davina Gruenstein Director, Public Relations Puget Sound Energy}

Davina Gruenstein is the director of public relations for Puget Sound Energy, Washington state's oldest and largest energy utility. She leads the company's communication efforts in emergency planning and preparation and is a strategic advisor in the utility's engagement with social media. 


\section{Walter Neary \\ Public Relations Director \\ Comcast}

Walter was a newspaper reporter and editor for 15 years in California and then Lakewood and Olympia where he spent a lot of his time covering courts and crime. He then worked six years in public relations for the University of Washington Medical Center and Health Sciences schools before joining Comcast six years ago. He manages the local Comcast community relations website and a variety of media and nonprofit sponsor relationships. He is also serving his second term on the Lakewood City Council, where he regularly uses social media. The latest issue of the Association of Washington Cities magazine says Walter is "perhaps one of the most social media-savvy elected officials in the state"

\section{Lind Simonsen Community Relations Coordinator Pierce County Transit}

Lind Simonsen is the Community Relations Coordinator for Pierce Transit and is responsible for communicating Pierce Transit's services and programs to community organizations and to the general public. He coordinates transit service in support of large community events and is well versed in local and regional transportation services and issues. He also is involved in community-wide disaster preparedness planning and Homeland Security activities.

Pierce Transit is the public transportation agency for Tacoma and Pierce County, providing local and express bus service, vanpools, park \& ride lots, and transportation for people with disabilities. Last year, Pierce Transit provided more than 16.8 million passenger trips. 


\section{James Graybeal \\ Director of Public Affairs \\ North American Aerospace Defense Command and United States Northern Command}

Mr. James W. Graybeal is the Director of Public Affairs for the Headquarters North American Aerospace Defense Command (NORAD) and United States Northern Command (USNORTHCOM), headquartered at Peterson Air Force Base, Colo. In addition to providing Public Affairs counsel to the NORAD and USNORTHCOM commander and senior staff, Mr. Graybeal provides timely and truthful information so the public, government leaders and the news media may better understand NORAD's aerospace warning and aerospace defense missions and USNORTHCOM's missions in providing homeland defense and defense support of civil authorities.

Mr. Graybeal served more than 23 years in the Navy before retiring in the rank of Captain in 2008. Prior to his current position, he served as the Chief of Public Affairs at U.S. Central Command (USCENTCOM) in Tampa, Fl. from 2007 to 2008 and at U.S. Strategic Command, Offutt Air Force Base, Neb. from 2004 to 2007. While at USCENTCOM, Mr. Graybeal directed the employment of all multi-national Public Affairs Officers deployed to Southwest and Central Asia in support of Operations IRAQI FREEDOM and ENDURING FREEDOM.

Mr. Graybeal graduated from Temple University in 1985 with a Bachelor of Arts Degree in Business Administration and holds a master's degree in National Security and Strategic Studies from the U.S. Naval War College.

In 1985, he began his Naval career through the Officer Candidate School program. That same year, he reported aboard USS PORTLAND (LSD 37) serving in various assignments and completing his qualifications as a Surface Warfare Officer.

Mr. Graybeal went on to attend the U.S. Naval Academy in 1989. Here is where he taught celestial navigation and offshore sailing to the Midshipmen Corps. His first tour as a Public Affairs Officer was at Navy Recruiting Area Three in Macon, Ga., from 1991 to 1993.

In 1993, Mr. Graybeal reported to USS THEODORE ROOSEVELT (CVN 71)/Commander Carrier Battle Group Eight. During this tour, he was responsible for media coverage of the U.S. Navy during OPERATION DELIBERATE FORCE in Bosnia Herzegovina and was detailed to USS EISENHOWER to escort media during the Army's 10th Mountain Division combat deployment to Haiti for OPERATION UPHOLD DEMOCRACY.

Mr. Graybeal joined the Office of the Assistant Secretary of Defense for Public Affairs in 1995. Here he served as a Plans Action Officer helping to prepare Secretary Perry to address Congress and the media following the Khobar Towers bombing and OPERATION DESERT FOCUS. It was here that he also contributed to the development and implementation of the Department's risk communications plan for the Anthrax Vaccination Program. Midway through this tour, he was recruited to serve as a Military Assistant for the Assistant Secretary. In this role, he served as the Public Affairs liaison to then Senator Cohen's transition team and later helped prepare Secretary Cohen to respond to the media after the U.S. Embassy bombings in Nairobi and Dar es Salaam. As well as planning, organizing and executing numerous media activities in direct support of the Secretary during overseas travel, he often traveled as the Secretary's press officer. 
Mr. Graybeal joined the Commander Naval Forces Japan staff in 1998. Here he developed a risk communications plan for a Human Health Risk Assessment at Naval Air Facility Atsugi and a crisis communication strategy for the toxic emissions from Enviro-Tech (Shinkampo) Incinerator. Additional challenges included a deployment to OPERATION VALIANT RETURN, the repatriation of an EP-3 crew detained in China and interaction with the families of victims of the Ehime Maru/USS GREENEVILLE collision.

In 2002, Mr. Graybeal was identified to be the Deputy Director of Public Affairs for the U.S. European Command where he developed and implemented a strategic communications plan for the controversial rebasing of the U.S. military in Europe and Africa. In 2003, he found himself serving the Commander of U.S. Naval Forces Central Command in Bahrain. In this position, he coordinated media activities during operations IRAQI and ENDURING FREEDOM and for theater-wide Maritime Security Operations conducted by the Combined Forces Maritime Component.

\section{Laurie Van Leuven Strategic Advisor and Manager Seattle Public Utilities City of Seattle}

Laurie Van Leuven is a strategic advisor and manager specializing in Security and Emergency Management for the City of Seattle, Public Utilities Department. She is responsible for physically securing utility assets and ensuring critical infrastructure protection for the regional drinking water system for 1.4 million people in Seattle and neighboring communities as well as protecting the wastewater, drainage and flood control, and solid waste / debris management systems in Seattle. Ms. Van Leuven has 10 years of experience in emergency management working with multiple first responder disciplines and serves as a Planning Section Chief on a regional, level three Incident Management Team. She is a member of the Interagency Board and the City of Seattle's Disaster Management Committee. Ms. Van Leuven earned her Master's degree from the Center for Homeland Defense and Security at the Naval Postgraduate School and holds a Bachelor's degree in Communications from the University of Washington. 


\section{Leng Caloh \\ Convergence Editor \\ KPBS}

Leng Caloh is Convergence Editor at KPBS San Diego. As Convergence Editor, she manages the Jacobs Project for Reporting Excellence, a multimedia fellowship program, and helps the station integrate its radio, television, and online platforms. Ms. Caloh has over 11 years of experience in online content development, and also spent several years producing television documentaries and public affairs programs. She has helped oversee the KPBS New Media team since its inception in 2006, and led the team through its coverage of the October 2007 wildfires. Leng was responsible for tapping into Twitter and Google Maps during the wildfires, which led to an APTRA Mark Twain Award for Breaking News Online. Ms. Caloh has received a CINE Golden Eagle as well as numerous first place awards for her broadcast and Web work from the local Society of Professional Journalists and the San Diego Press Club.

\section{Joseph Spurr Web Developer KPBS}

Joe Spurr is a web developer/designer and a writer. His bylined work has appeared in The Boston Globe and the IT news magazine TechTarget, among other publications. He holds a bachelor's degree in Journalism from Northeastern University in Boston, where he was born and raised.

Joe currently lives in San Diego and is a web developer/producer for KPBS, where he is charged among other duties with helping cultivate "the journalistic practices of tomorrow" vis-à-vis the Jacobs Project for Reporting Excellence.

Past projects include leading the station to experiment with Twitter in 2007, which set the stage for KPBS' lauded adoption of Twitter during the October wildfires. Joe also created the station's first Google My Map in Sept. 2007, which in the face of drought compiled public data and used color-coded placemarks to show the current percentage of capacity for 26 San Diego-area reservoirs. This laid foundation for the nationally-recognized Google Map of the wildfires, which helped residents track and make sense of the evolving chaos. Since then, Joe reported from and experimented with backpack journalism techniques at the 2008 RNC and DNC. He leveraged the Google Maps API and hand-built XML files to build complex, layered maps to track the explosion of drug-related violence in Tijuana, a centerpiece of Amy Isackson's award-winning Border Battle project. He was lead developer on kpbs.org's first in-house redesign, launched in May of 2009 under a strict accessibility mandate. He is currently most interested in the transparent government movement as it relates to cultivating the semantic web: the push to publish information in a way that is open and machine-readable, so that we can extract meaning from data in a way that is trustworthy, efficient, and compelling. 


\section{Sabra Schneider \\ Web Master \\ King County}

Sabra Schneider currently manages online communications for the King County government and is responsible for the development and management of social media county-wide. Ms. Schneider also teaches communications at South Seattle Community College. She has presented nationally and regionally on using social media in local government, leveraging technology in education and the intersection of communications, technology and government. Ms. Schneider has a Master's in Public Administration from the Evans School of Public Affairs at the University of Washington and a Bachelors Degree in Multimedia Communications from the University of California, Santa Cruz.

\section{Edward Vassallo Ready Coordinator City of Philadelphia}

Educating the citizens of Philadelphia on the importance of emergency preparedness is the responsibility of Edward Vassallo. As the Ready Coordinator for the Philadelphia Office of Emergency Management, he promotes the Ready Philadelphia campaign, which focuses on preparing the public for all possible emergencies. Through brochures, a website, media events, community outreach and social networking, he enables the citizens to know what to have in their head, home and hand during an emergency.

Ed joined OEM in June 2008 after years in print media and public relations. He also holds a BA in Journalism from Penn State University. 


\section{Appendix D Invited Participants}

Sheri Badger

Pierce County Emergency Management

Jon Barr

Pacific Northwest National Laboratory

Kim Blakely

Valley Medical Center

Laura Blaske

Washington State Department of Health

Sharon Bogan

Public Health-Seattle and King County

Diane Bonne

Puget Sound Regional Catastrophic

Preparedness Grant Program

Raymond Bunk

City of Federal Way Police Department

Tony Calero

King County Office of Emergency Management

Leng Caloh

KPBS San Diego

Jared Chase

Pacific Northwest National Laboratory

Rebecca Clark

City of Bellevue

Kirsten Clemens

Bothell Fire and Emergency Medical Services

Dave Dehaan

Everett Emergency Management

Peter Di Turi

Seattle Fire Department

Cynthia Dold

Public Health-Seattle and King County
August Drake-Ericson

Seattle Parks and Recreation Department

Wayne Einfeld

Sandia National Laboratories

Alice Fiman

Washington State Department of Transportation

James Fogarty

King County Medic One

T. Joseph Fountain

Seattle Police Department

David Franco

Sandia National Laboratories

Gary Gibson

City of Seattle Department of Information

Melanie Godinez

Pacific Northwest National Laboratory

Debbie Goetz

Seattle Office of Emergency Management

Chris Gough

Seattle Police Department

Patricia Graesser

Seattle District, U.S. Army Corps of Engineers

Barb Graff

Seattle Office of Emergency Management

James Graybeal

USNORTHCOM, NORAD

Davina Gruenstein

Puget Sound Energy

Sherry Hamilton

King County Department of Community and Human Services 
Brandon Hardenbrook

Pacific Northwest Economic Region

Eric Holdeman

Port of Tacoma

Penny Hulse

Gig Harbor Fire and Medic One

Carla Iafrate

Bellevue Police Department

Elenka Jarolimek

City of Seattle, Fleets and Facilities Department

Debra Jelcick

Washington State Fusion Center/Seattle Police

Department

Mart Kask

Thurston County Emergency Management

Kendra Kay

South King Fire and Rescue

Brian Kemper

Seattle Department of Transportation

Heather Kelly

King County Office of Emergency Management

Karen Kim

American Red Cross Mount Rainier Chapter

Jenna Larson

Pacific Northwest National Laboratory

Larry Leeson

Battelle

Ann Lesperance

Pacific Northwest National Laboratory

Fay Lim

King County

William Llewellyn

Madigan Army Medical Center

Michael Loehr

Public Health-Seattle and King County
Pat Lowery

Kent Police Department

Ericka Lund

Seattle Office of Emergency Management

Regina Lundgren

Communication Consultant and Trainer

Smith Lutu

Seattle Parks and Recreation Department

Lois Maag

City of Seattle, Department of Neighborhoods

Mark MacIntyre

U.S. Environmental Protection Agency

Lynne Miller

King County Emergency Management

Brittany Minker

Pierce County Emergency Management

Autumn Monahan

City of Issaquah

John Mower

Cubic Applications, Inc.

Nicholas Murphy

Seattle Fire Department

Kenneth Neafcy

Seattle Office of Emergency Management

Walter Neary

Comcast

Peg Nielsen

Seattle Department of Transportation

Sean Nolan

Defense Threat Reduction Agency

Greg Nordlund

Washington State Department of Health

Lise Northey

Regional Catastrophic Preparedness Program 


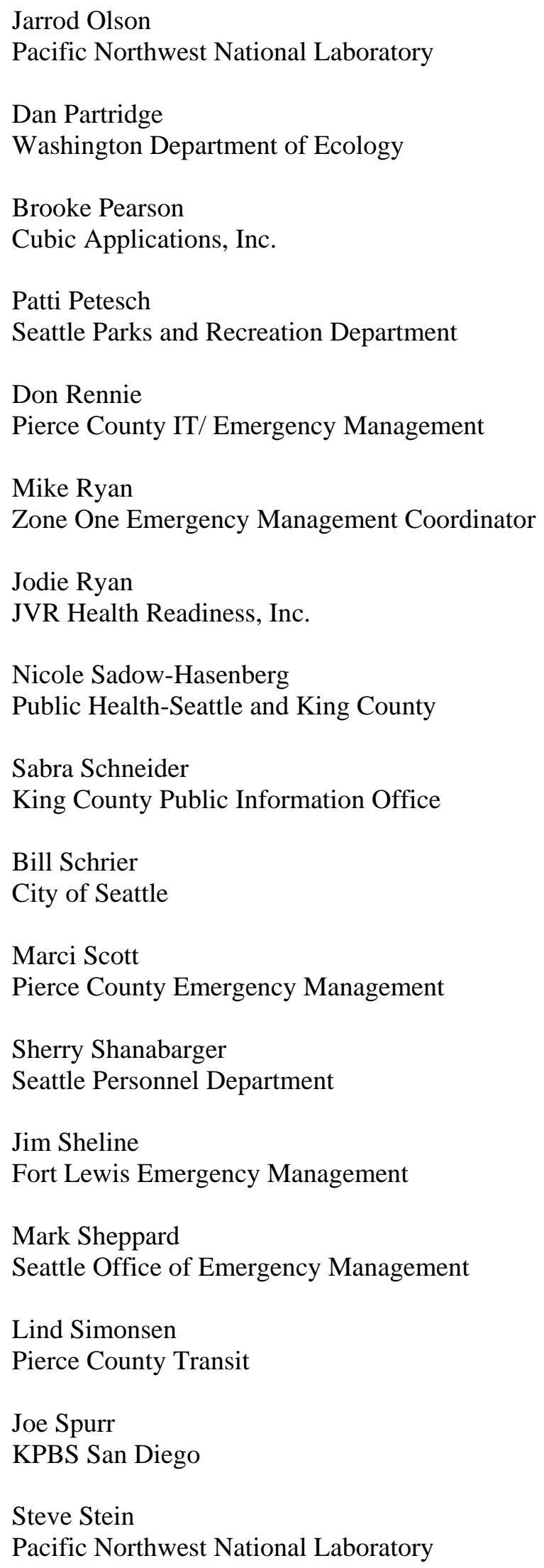

\author{
Grant Tietje \\ Seattle Office of Emergency Management \\ Chris Toomey \\ Pacific Northwest National Laboratory \\ Wayne Turnberg \\ Washington State Department of Health \\ Marybeth Turner \\ Seattle Department of Transportation \\ Stacy Tyler \\ Cubic Applications, Inc. \\ Doug Vandergiessen \\ Seattle Police Department \\ Jeff Vandergiessen \\ Mars Hill Church \\ Laurie Van Leuven \\ Seattle Public Utilities \\ Edward Vassallo \\ Philadelphia Office of Emergency Management \\ Kristi Weaver \\ South King Fire and Rescue \\ Joseph Weston \\ Madigan Army Medical Center \\ Sean Whitcomb \\ Seattle Police Department \\ Josie Williams \\ Eastside Fire and Rescue \\ Mark Williamson \\ Fort Lewis Emergency Management \\ Joby Winans \\ Tacoma Pierce County Health Department \\ Glen Woodbury \\ Naval Postgraduate School \\ Adam Wynne \\ Pacific Northwest National Laboratory
}




\section{Appendix E Acronyms}

CHDS Center for Homeland Defense and Security

DHS U.S. Department of Homeland Security

DOD U.S. Department of Defense

EPA Environmental Protection Agency

FEMA Federal Emergency Management Agency

IBRD Interagency Biological Restoration Demonstration Project

IPA Inter-Personnel Agreement

KPBS San Diego’s public media outlet

NORAD North American Aerospace Defense Command

PNNL Pacific Northwest National Laboratory

PSE Puget Sound Energy

USNORTHCOM United States Northern Command 


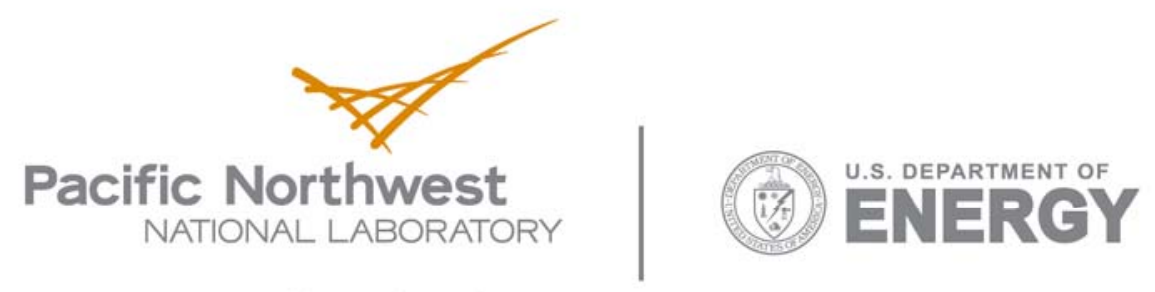

902 Battelle Boulevard

P.O. Box 999

Richland, WA 99352

1-888-375-PNNL (7665)

www.pnl.gov 